NBER WORKING PAPER SERIES

\title{
AN EQUILIBRIUM MODEL OF HOUSING AND MORTGAGE MARKETS WITH STATE-CONTINGENT LENDING CONTRACTS
}

\author{
Tomasz Piskorski \\ Alexei Tchistyi \\ Working Paper 23452 \\ http://www.nber.org/papers/w23452 \\ NATIONAL BUREAU OF ECONOMIC RESEARCH \\ 1050 Massachusetts Avenue \\ Cambridge, MA 02138 \\ May 2017
}

First Draft: April 2016. Piskorski acknowledges financial support from the National Science Foundation and the Paul Milstein Center for Real Estate at Columbia Business School. The views expressed herein are those of the authors and do not necessarily reflect the views of the National Bureau of Economic Research.

NBER working papers are circulated for discussion and comment purposes. They have not been peer-reviewed or been subject to the review by the NBER Board of Directors that accompanies official NBER publications.

(C) 2017 by Tomasz Piskorski and Alexei Tchistyi. All rights reserved. Short sections of text, not to exceed two paragraphs, may be quoted without explicit permission provided that full credit, including () notice, is given to the source. 
An Equilibrium Model of Housing and Mortgage Markets with State-Contingent Lending Contracts

Tomasz Piskorski and Alexei Tchistyi

NBER Working Paper No. 23452

May 2017

JEL No. D1,D5,E44,G01,G21,G28

\begin{abstract}
We develop a tractable general equilibrium framework of housing and mortgage markets with aggregate and idiosyncratic risks, costly liquidity and strategic defaults, empirically relevant informational asymmetries, and endogenous mortgage design. We show that adverse selection plays an important role in shaping the form of an equilibrium contract. If borrowers' homeownership values are known, aggregate wages and house prices determine the optimal statecontingent mortgage payments, which efficiently reduces the costs of liquidity default. However, when lenders are uncertain about homeownership values, the equilibrium contract only depends on house prices and takes the form of a home equity insurance mortgage (HEIM) that eliminates the strategic default option and insures the borrower's equity position. Interestingly, we show that widespread adoption of such loans has ambiguous effects on the homeownership rate and household welfare. In economies in which recessions are expected to be severe, the HEIM equilibrium Pareto dominates the equilibrium with fixed-rate mortgages. However, if economic downturns are not severe, HEIMs can lower the homeownership rate and make some marginal home buyers worse-off. We also note that adjustable-rate mortgages (ARMs) may share some benefits with HEIMs, which may help justify a high concentration of ARMs among riskier borrowers. Finally, we find that unrestricted competition between lenders may lead to a nonexistence of equilibrium. This suggests that government-sponsored enterprises may stabilize mortgage markets by subsidizing certain mortgage contracts.
\end{abstract}

Tomasz Piskorski

Columbia Business School

3022 Broadway

Uris Hall 810

New York, NY 10027

and NBER

tp2252@columbia.edu

Alexei Tchistyi

College of Business

University of Illinois

340 Wohlers Hall

Champaign, 6182 IL

tchistyi@illinois.edu 


\section{Introduction}

Residential mortgage contracts are of first-order importance for households, financial institutions, and for the broader economy. The Great Depression of 1929-1939 showed that forms of mortgage lending are extremely important to how the economy responds to shocks. At that time, mortgage contracts were predominantly short-term loans. The inability to roll them over was a major contributor to the collapse of the financial and housing markets. In response to the lessons learned from the Great Depression, federal regulators developed long-term fully amortizing fixed rate mortgage contracts, also known as FRMs, which have become the most popular form of mortgage lending in the United States. ${ }^{1}$

The recent Great Recession associated with millions of costly foreclosures has led to a revival of the debate regarding the appropriate structure of residential lending contracts. A key lesson from the Great Recession is that the rigidity of mortgage contract terms coupled with a variety of frictions preventing effective renegotiation or refinancing of loans of vulnerable borrowers may have exacerbated the foreclosure crisis and the severity of the economic downturn (e.g., Piskorski et al. 2010; Agarwal et al. 2012, 2015; Keys et al. 2013; Mayer et al. 2014; Scharfstein and Sunderam 2016). ${ }^{2}$ At the core of this debate are a variety of proposals concerning the redesign of mortgage contracts so that they allow for more efficient sharing of aggregate risk between borrowers and lenders to lower the incidence of costly foreclosures and the severity of future housing downturns (e.g., Shiller 2008; Caplin et al. 2008; Piskorski and Tchistyi 2011; Campbell 2013; Keys et al. 2013; Mian and Sufi 2014; Eberly and Krishnamurty 2014).

Despite the fundamental importance of this question, there is little theoretical analysis investigating the effects of a widespread adoption of state-contingent lending contracts in a general equilibrium setting with aggregate uncertainty. The life-cycle models of mortgage contract choice (e.g., Campbell and Cocco 2003, 2015) and mortgage design studies of state-contingent contracts employing dynamic contracting tools (e.g., Piskorski and Tchistyi 2010, 2011) commonly adopt a partial equilibrium perspective that takes some key variables such as house prices as given. How-

\footnotetext{
${ }^{1}$ See Green and Wachter (2005) for more discussion of the historical evolution of mortgage contracts in the U.S.

${ }^{2}$ These frictions include barriers to loan renegotiation due to securitization (Piskorski et al. 2010), lenders' concerns regarding borrowers' strategic behavior that can limit ex-post loan work-outs (Mayer et al. 2014), and the limited organizational ability of servicers to provide debt relief to a large number of borrowers in a crisis (Agarwal et al. 2012). In addition, borrowers with FRMs left with little housing equity can be ineligible for loan refinancing, and limited competition in the refinancing market may adversely affect the effectiveness of polices aimed at facilitating loan refinancing activity during economic downturns (Agarwal et al. 2015; Scharfstein and Sunderam 2016).
} 
ever, developments in the mortgage lending market, due to its large size, can have pronounced effects on house prices, construction, home ownership rates, and the allocation of credit in the economy feeding back into mortgage market outcomes.

To study such effects, we develop a tractable general equilibrium framework of housing and mortgage markets in a setting with aggregate and idiosyncratic risks, costly liquidity and strategic defaults, empirically relevant informational asymmetries, endogenous housing supply and home prices, and endogenous mortgage design. ${ }^{3}$ In this respect, our work is complementary with recent quantitative dynamic equilibrium models of housing markets with heterogenous agents and aggregate risk (e.g., Favilukis, Ludvingson, Van Nieuwerburgh 2016; Kaplan, Mitman, and Violante 2016) and contemporaneous research that studies the role of mortgage contracts in such settings (e.g., Greenwald, Landvoigt, and Van Nieuwerburgh 2017; Guren, Krishnamurty, and McQuade 2017). ${ }^{4}$ Such models can provide many valuable insights including the quantitative assessment of various effects. However, their complex settings usually require the use of numerical methods to analyze equilibria. This makes it hard to derive results analytically and to study the impact of factors such as informational asymmetries and competition among lenders on endogenous mortgage design and other equilibrium outcomes. ${ }^{5}$ In this regard, our objective is to develop a framework that is rich enough to capture the complex interplay of various factors in a market equilibrium while still being tractable enough to develop key qualitative insights transparently including a set of closed form solutions. We hope that this framework could be used in future research on housing and mortgage markets.

In our setting the economy is subject to aggregate productivity shocks that determine the capital returns and aggregate wages. Households need financing from owners of capital to buy homes. We incorporate two sources of informational asymmetries between borrowers and lenders that were documented to be quantitatively important by empirical literature. ${ }^{6}$ First, we assume

\footnotetext{
${ }^{3}$ Our paper is related to a large literature on financing models with informational asymmetries (e.g., Stiglitz and Weiss 1981; Diamond 1984; Bolton and Scharfstein 1990; DeMarzo and Sannikov 2006; DeMarzo and Fishman 2007, Biais et al. 2007; Farhi, Golosov, and Tsyvinski 2009) and to the literature studing the role of collateral, leverage, and default in various equilibrium settings (e.g., Kiyotaki and Moore 1997; Dubey et al. 2005; Rampini and Viswanathan 2010; Makarov and Plantin 2013; Brunnermeier and Sannikov 2014; He and Milbradt 2014; Bolton et al. 2016).

${ }^{4}$ In this regard, our paper is also related to Kung (2015) who explores a number of counterfactuals related to credit availability and mortgage contract forms in a quantitative equilibrium model of the housing market.

${ }^{5}$ In dynamic quantitative equilibrium models with aggregate uncertainty and individual heterogeneity the fully rational equilibrium is usually not computable as a large number of agents typically face an infinite dimensional state space (e.g., see Favilukis et al. 2016).

${ }^{6}$ The empirical literature has documented that informational asymmetries are a pervasive feature of the housing finance market. For recent evidence see, among others, Keys et al. (2010), Jiang et al. (2014), Garmaise (2015),
} 
that households differ in the private value they attach to homeownership. Second, after obtaining their loans, the households will be subject to individual private productivity shocks leading to hardto-verify variation in their disposable income. To provide borrowers with incentives to repay their loans the lenders have to repossess properties of delinquent borrowers, which results in deadweight losses. Consequently, in equilibrium borrowers may default due to both liquidity (inability to pay) and strategic (unwillingness to pay) reasons. ${ }^{7}$ Our setting that incorporates the informational asymmetries in the mortgage lending market relates to earlier real estate finance literature that recognized the importance of informational asymmetries for mortgage contract terms (e.g., Dunn and Spatt 1985, 1988; Chari and Jagannathan 1989; Stanton and Wallace 1998).

The model timing is as follows. At time 0, before the aggregate and idiosyncratic shocks are realized the households obtain loans from competitive lenders. In the intermediate period $(0+)$, the aggregate and idiosyncratic shocks are realized, affecting the equilibrium returns to capital, wages, and households repayment decisions. The lenders repossess homes of delinquent borrowers. At time 1, the secondary market for homes is open, where homeowners and lenders with repossessed inventory can sell their homes. The potential buyers include renters and households who lost their homes to foreclosures.

We first consider a market equilibrium when the lenders are restricted to only offer fixed-rate mortgage contracts. As expected, mortgage defaults are lower and equilibrium house prices are higher in good economic times. Interestingly, an equilibrium with FRM contracts features strategic defaults in the bad economic state by borrowers with relatively low homeownership values. Because homeownership value is private, the FRM equilibrium has borrowers with high homeownership values effectively cross-subsidizing those with lower values.

In addition, we show that with convex construction costs a decline in cost of credit can contribute to an initial house price boom and a subsequent decline in house prices. Intuitively, cheaper credit leads to higher demand resulting in higher housing construction and higher initial house prices. However, a higher housing supply puts a downward pressure on home prices in the secondary market, which can lead to significantly lower housing prices in the subsequent period.

As an intermediate step towards the equilibrium with state-contingent mortgages, we derive

Piskorski et al. (2015), Griffin and Maturana (2016), Stroebel (2016).

${ }^{7}$ The empirical literature suggests that both reasons played an important role in accounting for mortgage default patterns during the Great Recession. While liquidity considerations coupled with the collapse of house prices are believed to play a dominant role, strategic motives may have accounted for more than $20 \%$ of mortgage defaults (see Keys et al. 2013). 
an optimal mortgage contract assuming the borrower's homeownership utility is known to be sufficiently high, so that the borrower will not default strategically. We find that a FRM contract is inefficient and that an optimal mortgage contract calls for the adjustment of repayment rates in proportion to movements in wages and house prices. Intuitively, when wages are higher, the borrowers can afford higher mortgage payments. Moreover, higher house prices in the good state imply that liquidity default is less costly to the lender due to the higher collateral value. A higher required payment in the good state allows a reduction of payments in the bad state, which reduces the overall chances of liquidity default and the associated deadweight losses.

Next, we characterize an equilibrium with no restrictions on mortgage forms assuming lenders cannot fully observe homeownership values of potential borrowers. The optimal state-contingent contract discussed above cannot be sustained in an equilibrium, since this contract would be attractive to borrowers with relatively low homeownership value who would strategically default with positive probability. More broadly, we show that the adverse selection associated with strategic defaulters implies that there cannot be strategic defaults in equilibrium with no restrictions on mortgage contract forms. As a result, the equilibrium contract takes the form of a home equity insurance mortgage (HEIM) that fully insures borrower's equity position against the movement in house prices and completely eliminates the strategic default option and associated default inefficiencies.

We also find that unrestricted competition between lenders may lead to a non-existence of equilibrium with state-contingent mortgage contracts. The equilibrium is less likely to exist when there are fewer households with homeownership values close to that of the marginal homebuyer and when wages in the bad state are much lower than those in the good state.

We finish our main analysis with a relative comparison of the equilibrium outcomes in an economy restricted to only FRM contracts to the one with no restrictions on mortgage contract form. Interestingly, we find that the homeownership rate is not necessarily higher and that some households can be worse off in the equilibrium with HEIM contracts. This is because FRMs come with the embedded strategic default option, which is valuable to marginal homebuyers. We further show that the impact of HEIMs on the welfare of borrowers is importantly tied to the severity of economic downturns. In the economies in which recessions are expected to be sufficiently severe (e.g., household incomes are sufficiently low in the bad state) HEIMs lead to an increase in the homeownership rate and higher welfare for all households compared to the FRM equilibrium. 
However, if economic downturns are not severe, a widespread adoption of HEIMs can lower the homeownership rate and make some marginal potential homeowners worse-off.

The rest of this paper is organized as follows. Section 2 presents the setup of our model. Section 3 characterizes the equilibrium with FRM contracts. Section 4 characterizes an optimal state-contingent contract in a setting where borrowers' homeownership values are known. Section 5 characterizes the equilibrium with state-contingent mortgage contracts in our main setting where lenders are uncertain about homeownership values. Section 6 studies the welfare implications of a widespread adoption of state-contingent contracts. Section 7 discusses the robustness of our findings and a number of possible extensions of our setting. Among other points, in Section 7, we note that adjustable-rate mortgage (ARM) contracts may share some benefits with HEIMs, which may help explain ARM popularity among riskier borrowers. We also note that in some cases imposing a restricted contract choice may help facilitate an existence of a stable market. Section 8 concludes.

\section{Model Setup}

For simplicity, we assume that there is only one generation of workers who live for two periods production and retirement. Production happens only in the first period, however the agents enjoy consumption and housing utility in both periods. Since workers have no assets in the first period they need to borrow from owners of capital to finance their housing purchases. They repay their loans during the first period. This simple setup allows us to analyze housing and mortgagee market equilibrium while maintaining the analytical tractability of the model.

In particular, we assume that there is a unit continuum of risk-neutral workers, living and consuming during two periods. Worker $i$ per period utility is given by

$$
u_{i, t}\left(c_{t}, h_{i, t}, \theta_{i}\right)=c_{t}+\theta_{i} 1_{h_{i, t}=1}
$$

where $c_{t}$ is consumption in period $t, h_{i, t}=1$ if worker $i$ is a homeowner in period $t$, and $h_{i, t}=0$ otherwise. For simplicity we assume that there is no time discounting and there is no disutility of labour. ${ }^{8}$ We normalize the cost and utility of rental to zero. ${ }^{9}$ In other words, homeownership

\footnotetext{
${ }^{8}$ Allowing for time discounting and disutility of labour have no qualitative impact on the results. We also note that risk neutrality assumption is not essential for our key findings (see Section 7.4).

${ }^{9}$ We could formally model the rental market with rents being determined by the equilibrium market clearing
} 
means living in a more expensive housing unit and enjoying additional utility $\theta_{i} \in[0, \bar{\theta}]$ because of it. Worker $i$ 's utility $\theta_{i}$ of owning a house for one period is his or her private information and remains constant for two periods. The utility of homeownership among workers is distributed according to the cumulative and probability density functions $F$ and $f$, with $f\left(\theta_{i}\right)>0$ for $\theta_{i} \in[0, \bar{\theta}]$.

Each workers supplies one unit of labor in the first period and retires in the second period. Workers's idiosyncratic labor productivity $l(i) \in[0,1]$ is i.i.d. across workers, with cdf $G(l)$, and pdf $g(l)>0$ for $l \in[0,1]$. The average idiosyncratic worker's labor productivity is denoted by

$$
L=\int_{0}^{1} l(i) g(i) d i
$$

Since there is a unit mass continuum of workers, $L$ is also the aggregate labor supply. For simplicity, assume that workers have no capital endowment.

In addition to the workers, the economy is also populated by risk-neutral capitalists who are endowed with capital $\bar{K}$ and do not work. The risk-neutral capitalists already have houses, which they will not sell. The capitalists can consume their capital, use it to build new houses, or invest it into production of the consumption good. The capitalists can also give mortgage loans to the workers.

Building one home requires $q$ units of capital. For simplicity, we assume that home production happens instantaneously at the beginning on the first period and does not require any labor.

Aggregate production of the consumption good in the first period is given by the linear production function with constant return to scale

$$
Y(K, L, s)=A^{K}(s) K+A^{L}(s) L
$$

where $A^{K}(s), A^{L}(s)$ are the total factor productivity of capital and labour in state $s$, respectively and $K$ is the capital allocated to the production. There are two states of the economy, "good" $s_{g}$ with probability $\pi_{g}$ and "bad" $s_{b}$ with probability $\pi_{b}=1-\pi_{g}$, and $A^{K}\left(s_{g}\right)>A^{K}\left(s_{b}\right)$ and $A^{L}\left(s_{g}\right)>A^{L}\left(s_{b}\right)$. As we discuss in Section 7.1 while the production function form (1) simplifies some of our arguments, our key findings should hold in a large class of production functions.

condition. However, as long as homeownership is sufficiently valuable relative to the rental option our key insights would remain unchanged. 
The timing of the events is as follows. At $t=0$, the capitalists allocate capital between production and housing. The workers decide whether to buy homes knowing their personal utility $\theta_{i}$ of homeownership, but before knowing the future state of the economy and their idiosyncratic labor productivity shocks. Homebuyers take on mortgages to finance the home purchases. Borrowers for whom buying a home given the financing terms yields them strictly higher utility relative to not buying, become homeowners at $t=0$.

At time $t=0+$, both macro and idiosyncratic labor productivity shocks are realized. The workers learn their income and decide whether to pay the mortgage or default and vacate their homes, which will remain unoccupied until the end of the first period. Defaults result in deadweight losses because foreclosed homes remain unoccupied for one period and their housing utility is lost.

At time $t=1$, the secondary market for homes clears. The supply includes all foreclosed homes in $t=0+$ and homes that the existing homeowners decide to put on the market. Renters including those who defaulted at time $t=0+$ decide whether to buy homes. There are no costs associated with real estate transactions.

One can interpret $t=0+$ as the immediate aftermath of the productivity shock, and $t=1$ is the long term equilibrium with the markets fully adjusted to the shock.

We assume perfect competition at the production, home building and financial sectors of the economy. The production function (1) implies that

$$
\begin{aligned}
& R(s)=A^{K}(s), \\
& w(s)=A^{L}(s),
\end{aligned}
$$

are the gross return on capital and the wage per unit of labor productivity in the state $s$, respectively. Both wage $w(s)$ and interest rate $R(s)$ are higher in the good state of the economy. The income of worker $i$ is equal to $w(s) l_{i}$.

Let

$$
\bar{R} \equiv \pi_{b} R\left(s_{b}\right)+\pi_{g} R\left(s_{g}\right)
$$

denote the expected return on the capital invested in the production sector. In equilibrium, the capitalists should earn the same expected return on mortgages and the capital invested in the 
production sector. The price of a home at time zero is equal to the construction cost

$$
P_{0}=q
$$

\section{Equilibrium with Fixed Rate Mortgages}

In this section we characterize an equilibrium in mortgage and housing markets when the only allowed mortgage contract is the fixed-rate mortgage (FRM). Under the FRM contract, the borrower must pay a fixed amount $\bar{m}$ in every state of the economy in period one. If the borrower does not repay the loan the foreclosure happens and the lender repossesses the home. We will use superscript $F$ to emphasize the key variables related to the FRM equilibrium. Below we define an equilibrium with FRMs .

Definition 1 An FRM equilibrium consists of the allocation of capital $K^{H}$ and $K$ into housing and production sectors, mortgage payment $\bar{m}$ and prices $\left\{w(s), R(s), P_{0}, P_{1}^{F}(s)\right\}$, such that taking the equilibrium prices and mortgage payment as given the following is true.

At time $t=0$, i.e., before aggregate and idiosyncratic shocks $s$ and $l$ are known:

(i) Capitalists expect the same return on their investments in housing and production sectors,

(ii) Households buy homes if and only if homeownership results in strictly higher expected utility compared to renting in period one,

(iii) The housing market clears at time $t=0$, i.e., all homes built by capitalists are bought by households;

At time $t=0+$, i.e., when aggregate and idiosyncratic shocks $s$ and $l$ are revealed:

(iv) Homeowners with income less than $\bar{m}$ default for liquidity reason,

(v) Homeowners with income greater than $\bar{m}$ default strategically if and only if default increases their utility;

At time $t=1$, i.e., after economic shocks are fully absorbed by the economy:

(vi) Homeowners with housing utility less than $P_{1}^{F}(s)$ sell their homes in state $s$,

(vii) Renters including those who defaulted at time $t=0+$ buy homes in state $s$ if their housing utility and their income are greater than $P_{1}^{F}(s)$, 
(viii) The housing market clears at time $t=1$, i.e., no homes are left unoccupied in the second period.

We start our analysis of the equilibrium by characterizing the borrowers' default decisions.

\subsection{Borrowers' default decisions}

Borrowers obtain mortgages at $t=0$ and decide whether to default at $t=0+$ knowing all shocks, as well as the equilibrium home price $P_{1}^{F}(s)$ at time $t=1$. If $w(s) l_{i}<\bar{m}$, borrower $i$ does not have money to pay the mortgage and liquidity default happens. ${ }^{10}$ In this case the borrower keeps his labor income, but loses housing utility $\theta_{i}$ in the first period. If $P_{1}^{F}(s) \leq w(s) l_{i}$, the defaulted borrower can buy a home at $t=1$ and enjoy housing utility $\theta_{i}$ in the second period. Thus, the utility of workers who experience liquidity default in state $s$ is given by:

$$
w(s) l_{i}+1_{w(s) l_{i} \geq P_{1}^{F}} \max \left(0, \theta_{i}-P_{1}^{F}(s)\right) .
$$

If $w(s) l_{i} \geq \bar{m}$, the borrower can repay the loan but may decide to default strategically, in which case his utility is the same as above ${ }^{11}$. If he pays the mortgage, his utility will be

$$
w(s) l_{i}-\bar{m}+\theta_{i}+\max \left(\theta_{i}, P_{1}^{F}(s)\right)
$$

where the last term reflects the fact that the borrower would sell the home at time $t=1$ when $P_{1}^{F}(s)>\theta_{i}$.

When the borrower obtains a lower utility from paying the mortgage, the borrower chooses strategic default. The following proposition summarizes simple rules for liquidity and strategic defaults.

Proposition 1 Borrowers default for liquidity reasons in state $s$ when

$$
\bar{m}>w(s) l_{i}
$$

\footnotetext{
${ }^{10}$ In principle borrowers who cannot repay their mortgages could also try to sell their homes in the secondary market to repay their loans. However, in equilibrium the required debt repayment is larger than the secondary market price $\left(m>P_{1}(s)\right.$ for any $\left.s\right)$ so this would not be possible.

${ }^{11} \mathrm{We}$ assume that mortgages are non-recourse loans.
} 
Borrowers default strategically in state $s$ when the following two conditions hold:

$$
\begin{aligned}
& \bar{m} \leq w(s) l_{i} \\
& \bar{m}>\theta_{i}+P_{1}^{F}(s) .
\end{aligned}
$$

Proof is in Appendix.

This condition (4) is very intuitive. If $P_{1}^{F}(s)<\theta_{i}$, the borrower will buy back home at $t=1$ if he defaults at $t=0+$. In this case the benefit of default is the money he saves on defaulting less cost of buying back the home: $\bar{m}-P_{1}^{F}(s)$. The cost is the lost housing utility $\theta_{i}$ due to not living in the house in the first period.

If $P_{1}^{F}(s)>\theta_{i}$, the borrower will not buy back the house. Instead, he will sell it at time 1, provided he does not default earlier. In this case, $\bar{m}>\theta_{i}+P_{1}^{F}(s)$ means that the benefit of default $\bar{m}$ has to be larger than housing utility $\theta_{i}$ in the first period plus the market value $P_{1}^{F}(s)$ of the house at $t=1$.

In an equilibrium, a borrower does not strategically default in both states at $t=0+$ since then he would not be better off if he were a renter at $t=0$. Hence strategic default can only occur in one of the states. Moreover, this state cannot be the one with higher home prices at $t=1$ as according to Proposition 1 this borrower would also default in the state with lower home prices. We summarize this observation in the proposition below.

Proposition 2 In an FRM equilibrium, strategic defaults can only occur in the state with lower home prices.

\subsection{Housing market}

At $t=0$, given home prices $P_{0}=q$ and mortgage repayment $\bar{m}$ worker $i$ decides whether to become a home owner or a renter. Since the state of the economy and the labor income are not known at that time, the worker's housing utility $\theta_{i}$ is the only relevant variable for this decision. As a result, there is a marginal homebuyer with housing utility $\underline{\theta}^{F}$ who is indifferent between buying and renting at $t=0$. Workers with $\theta>\underline{\theta}^{F}$ will get a mortgage $\bar{m}$ and buy homes at $t=0$. Workers with $\theta \leq \underline{\theta}^{F}$ will initially rent, but may decide to buy at $t=1$.

We note that home prices $P_{1}^{F}(s)$ in each state $s$ at time $t=1$ cannot be greater than the housing utility of the marginal home buyer $\underline{\theta}^{F}$. If $P_{1}^{F}(s) \geq \underline{\theta}^{F}$, then workers with $\theta \in\left(\underline{\theta}^{F}, P_{1}^{F}(s)\right)$ 
will put their houses on the market in state $s$. However, workers with $\theta<\underline{\theta}^{F}$ will not buy them because their housing utility is lower than the price, and workers with $\theta>P_{1}^{F}(s)$ will not buy them because they are already homeowner. Thus, it must be the case that $P_{1}^{F}(s)<\underline{\theta}^{F}$ for the market to clear in an equilibrium.

Since $P_{1}^{F}(s)<\underline{\theta}^{F}$, only foreclosed homes will be offered for sale at $t=1$. In addition, $P_{1}^{F}(s)<$ $\underline{\theta}^{F}$ means that if homeowners default at $t=0+$, they will buy houses again at time $t=1$ if they have enough income.

The marginal homebuyer will strategically default effectively becoming a renter in the state with lower prices. Thus, in order for the marginal homebuyer to be indifferent between renting and buying at $t=0$, the marginal homebuyer has to be indifferent between renting and buying in the state with higher prices, which we denote by $s^{*}$. Hence, it must be the case that

$$
\underline{\theta}^{F}=\bar{m}-P_{1}^{F}\left(s^{*}\right) \text {. }
$$

Indeed, $\underline{\theta}^{F}$ is the housing utility, and $\bar{m}-P_{1}^{F}\left(s^{*}\right)$ is the savings from being a renter in the first period. Equation (5) also implies that $P_{1}^{F}(s)<\bar{m}$ for both $s$.

The defaulted homes will be offered for sale at $t=1$. We remember that strategic default can happen only in the state with lower prices. As a result, the aggregate supply of homes in the state $s^{*}$ associated with with higher prices will be

$$
\left(1-F\left(\underline{\theta}^{F}\right)\right) G\left(\frac{\bar{m}}{w\left(s^{*}\right)}\right)
$$

where $\left(1-F\left(\underline{\theta}^{F}\right)\right)$ is the number of home built and sold at $t=0$, and $G\left(\frac{\bar{m}}{w\left(s^{*}\right)}\right)$ is the fraction of the homeowners who defaulted due to liquidity reasons at $t=0+$.

The homes will be bought by the first time homebuyers with housing utility $\theta \in\left(P_{1}^{F}\left(s^{*}\right), \underline{\theta}^{F}\right)$ and idiosyncratic income shocks $l \geq \frac{P_{1}^{F}\left(s^{*}\right)}{w(s)}$. In addition, borrowers with $\theta>\underline{\theta}^{F}$ who defaulted at $t=0+$ will buy homes again at $t=1$ if $l \in\left(\frac{P_{1}^{F}\left(s^{*}\right)}{w\left(s^{*}\right)}, \frac{\bar{m}}{w\left(s^{*}\right)}\right)$. As a result, the aggregate demand will be

$$
\left(F\left(\underline{\theta}^{F}\right)-F\left(P_{1}^{F}\left(s^{*}\right)\right)\right)\left(1-G\left(\frac{P_{1}^{F}\left(s^{*}\right)}{w\left(s^{*}\right)}\right)\right)+\left(1-F\left(\underline{\theta}^{F}\right)\right)\left[G\left(\frac{\bar{m}}{w\left(s^{*}\right)}\right)-G\left(\frac{P_{1}^{F}\left(s^{*}\right)}{w\left(s^{*}\right)}\right)\right] .
$$

In the equilibrium, the supply equals the demand. Thus, in the state with high home prices the 
market clearing condition is given by

$$
\left(F\left(\underline{\theta}^{F}\right)-F\left(P_{1}^{F}\left(s^{*}\right)\right)\right)\left(1-G\left(\frac{P_{1}^{F}\left(s^{*}\right)}{w\left(s^{*}\right)}\right)\right)=\left(1-F\left(\underline{\theta}^{F}\right)\right) G\left(\frac{P_{1}^{F}\left(s^{*}\right)}{w\left(s^{*}\right)}\right) .
$$

In the state with low home prices, denoted by $s^{\prime}$, borrowers with $\theta \in\left[\underline{\theta}^{F}, \hat{\theta}^{F}\right)$ will default strategically even though they can afford to pay the mortgage, where

$$
\hat{\theta}^{F}=\bar{m}-P_{1}^{F}\left(s^{\prime}\right)
$$

and $P_{1}^{F}\left(s^{\prime}\right) \leq P_{1}^{F}\left(s^{*}\right)$. In addition, some borrowers with $\theta \geq \hat{\theta}^{F}$ will default for liquidity reasons, when $l_{i}<\frac{\bar{m}}{w\left(s^{\prime}\right)}$. As a result, the aggregate supply of homes in the bad state will be

$$
\left(F\left(\hat{\theta}^{F}\right)-F\left(\underline{\theta}^{F}\right)\right)+\left(1-F\left(\hat{\theta}^{F}\right)\right) G\left(\frac{\bar{m}}{w\left(s^{\prime}\right)}\right) .
$$

Workers with $\theta>P_{1}^{F}\left(s^{\prime}\right)$ who are not homeowners will buy homes at $t=1$ if they have enough income, i.e., $l \geq \frac{P_{1}^{F}\left(s^{\prime}\right)}{w\left(s^{\prime}\right)}$. Thus, the aggregate demand in the state with low home prices will be $\left(F\left(\underline{\theta}^{F}\right)-F\left(P_{1}^{F}\left(s^{\prime}\right)\right)\right)\left(1-G\left(\frac{P_{1}^{F}\left(s^{\prime}\right)}{w\left(s^{\prime}\right)}\right)\right)+\left(F\left(\hat{\theta}^{F}\right)-F\left(\underline{\theta}^{F}\right)\right)\left(1-G\left(\frac{P_{1}^{F}\left(s^{\prime}\right)}{w\left(s^{\prime}\right)}\right)\right)+\left(1-F\left(\hat{\theta}^{F}\right)\right)\left[G\left(\frac{\bar{m}}{w\left(s^{\prime}\right)}\right)-G\left(\frac{P_{1}^{F}\left(s^{\prime}\right)}{w\left(s^{\prime}\right)}\right)\right]$,

where the first term represents the demand from the first time homebuyers with housing utility $\theta \in$ $\left(P_{1}^{F}\left(s^{\prime}\right), \underline{\theta}^{F}\right)$, the second term represents the demand from the homeowners with $\theta \in\left(\underline{\theta}^{F}, \hat{\theta}^{F}\right)$ who (strategically) defaulted at $t=0+$, and the last term represents the demand from the homeowners with $\theta>\hat{\theta}^{F}$ who defaulted for liquidity reasons at $t=0+$.

Equating the supply and demand and cancelling terms on both sides gives the following equation for $P_{1}^{F}\left(s^{\prime}\right)$ :

$$
\left(F\left(\underline{\theta}^{F}\right)-F\left(P_{1}^{F}\left(s^{\prime}\right)\right)\right)\left(1-G\left(\frac{P_{1}^{F}\left(s^{\prime}\right)}{w\left(s^{\prime}\right)}\right)\right)=\left(1-F\left(\underline{\theta}^{F}\right)\right) G\left(\frac{P_{1}^{F}\left(s^{\prime}\right)}{w\left(s^{\prime}\right)}\right) .
$$

The market clearing equations (6) and (7) for the two states are similar because workers who default for liquidity or strategic reason at time $t=0+$ reenter the housing market at time $t=1$. The main difference between these equations is that wages are higher in the good state. This means that home prices are higher in the good state, i.e., $s^{*}=s_{g}$ (see the proof of Proposition 3 in Appendix).

We summarize these findings in Proposition 3. 
Proposition 3 In an FRM equilibrium, $1-F\left(\underline{\theta}^{F}\right)$ homes are built at time zero and the price of one home is $P_{0}=q$. Workers with $\theta \leq \underline{\theta}^{F}$ become renters, while workers with $\theta>\underline{\theta}^{F}$ take FRMs and buy homes, where

$$
\underline{\theta}^{F}=\bar{m}-P_{1}^{F}\left(s_{g}\right)
$$

At time $t=0+$ workers with $\underline{\theta}^{F}<\theta<\hat{\theta}^{F}$ strategically default, where

$$
\hat{\theta}^{F}=\bar{m}-P_{1}^{F}\left(s_{b}\right)
$$

At time $t=1$ only foreclosed homes are offered for sale. Home prices are higher in the good state:

$$
P_{1}^{F}\left(s_{g}\right)>P_{1}^{F}\left(s_{b}\right)
$$

and satisfy

$$
\begin{aligned}
& \left(F\left(\underline{\theta}^{F}\right)-F\left(P_{1}^{F}\left(s_{g}\right)\right)\right)\left(1-G\left(\frac{P_{1}^{F}\left(s_{g}\right)}{w\left(s_{g}\right)}\right)\right)=\left(1-F\left(\underline{\theta}^{F}\right)\right) G\left(\frac{P_{1}^{F}\left(s_{g}\right)}{w\left(s_{g}\right)}\right), \\
& \left(F\left(\underline{\theta}^{F}\right)-F\left(P_{1}^{F}\left(s_{b}\right)\right)\right)\left(1-G\left(\frac{P_{1}^{F}\left(s_{b}\right)}{w\left(s_{b}\right)}\right)\right)=\left(1-F\left(\underline{\theta}^{F}\right)\right) G\left(\frac{P_{1}^{F}\left(s_{b}\right)}{w\left(s_{b}\right)}\right) .
\end{aligned}
$$

Proof of equation (8a) is in Appendix.

Proposition 3 shows that FRM contracts embed a strategic default option. While this option creates inefficiencies due to strategic defaults in the bad state, it benefits the borrowers with lower homeownership values $\theta \in\left(\underline{\theta}^{F}, \hat{\theta}^{F}\right]$, which contributes positively to the homeownership rate $\underline{\theta}^{F}$. As a result, borrowers with higher homeownership values $\left(\theta \geq \hat{\theta}^{F}\right)$ end up cross-subsidizing the low $\theta$ borrowers.

Threshold $\underline{\theta}^{F}$ determines the homeownership rate $1-F\left(\underline{\theta}^{F}\right)$ in the economy, i.e., the fraction of households who are homeowners at time $t=0$ and $t=1$. The higher $\underline{\theta}^{F}$, the lower the homeownership rate.

\subsection{Equilibrium FRM contract}

The capitalists issue mortgages before knowing the future state of the economy. They lend $P_{0}$ to borrowers, who promise to pay back $\bar{m}$. However, if a borrower defaults, the capitalist's payoff in 
state $s$ is going to be $\bar{P}(s)<\bar{m} \cdot{ }^{12}$ In an equilibrium, the expected return on a mortgage is equal to the expected return $\bar{R}$ on capital invested in the production sector.

The expected mortgage payment in the good state, in which there are no strategic defaults, is:

$$
\Pi\left(s_{g}, \bar{m}\right)=\left(1-G\left(\frac{\bar{m}}{w\left(s_{g}\right)}\right)\right) \bar{m}+G\left(\frac{\bar{m}}{w\left(s_{g}\right)}\right) P_{1}^{F}\left(s_{g}\right) .
$$

In the bad state, all borrowers with $\theta \in\left(\underline{\theta}^{F}, \hat{\theta}^{F}\right)$ default. As a result, the expected mortgage payment is:

$$
\hat{\Pi}\left(s_{b}, \bar{m}\right)=\left(\frac{F\left(\hat{\theta}^{F}\right)-F\left(\underline{\theta}^{F}\right)}{1-F\left(\underline{\theta}^{F}\right)}\right) P_{1}^{F}\left(s_{b}\right)+\left(\frac{1-F\left(\hat{\theta}^{F}\right)}{1-F\left(\underline{\theta}^{F}\right)}\right)\left(\left(1-G\left(\frac{\bar{m}}{w\left(s_{b}\right)}\right)\right) \bar{m}+G\left(\frac{\bar{m}}{w\left(s_{b}\right)}\right) P_{1}^{F}\left(s_{b}\right)\right) .
$$

The equilibrium FRM is the smallest $\bar{m}$ that satisfies the lender's break even condition:

$$
P_{0} \bar{R}=\pi_{g} \Pi\left(s_{g}, \bar{m}\right)+\pi_{b} \hat{\Pi}\left(s_{b}, \bar{m}\right) .
$$

Throughout the paper we will use functions $\Pi(s, m)$ and $\hat{\Pi}(s, m)$ to denote lenders' payoffs in the state without strategic defaults and in the state with strategic defaults correspondingly. ${ }^{13}$ One can see that strategic defaults reduce the expected payoff to the lender. Indeed, $\hat{\Pi}\left(s_{b}, \bar{m}\right)$ can be rewritten as

$$
\hat{\Pi}\left(s_{b}, \bar{m}\right)=\Pi\left(s_{b}, \bar{m}\right)-\frac{\left(F\left(\hat{\theta}^{F}\right)-F\left(\underline{\theta}^{F}\right)\right)}{\left(1-F\left(\underline{\theta}^{F}\right)\right)}\left(1-G\left(\frac{\bar{m}}{w\left(s_{b}\right)}\right)\right)\left(\bar{m}-P_{1}^{F}\left(s_{b}\right)\right)<\Pi\left(s_{b}, \bar{m}\right),
$$

where $\Pi\left(s_{b}, \bar{m}\right)$ is the lender's expected payoff in the bad state in the absence of strategic defaults.

\subsection{A uniform example}

Here we assume that both $\theta$ and $l$ are uniformly distributed on $[0,1]$, i.e., $F(\theta)=\theta$, and $G(l)=l$. We will refer to this setup as the uniform example throughout the paper ${ }^{14}$.

\footnotetext{
${ }^{12}$ We assume no additional foreclosure costs for lenders.

${ }^{13}$ Unlike the FRM equilibrium, in which strategic defaults can occur only in the bad state, in an equilibrium with state contingent mortgage contracts strategic defaults can occur in the good state.

${ }^{14}$ In the uniform example, one has to check that $P_{1}(s), \frac{P_{1}(s)}{w(s)}, \underline{\theta} \in[0,1]$.
} 
With the uniform distribution functions, equation (9) becomes

$$
\left(\underline{\theta}^{F}-P_{1}^{F}\left(s_{g}\right)\right)\left(1-\frac{P_{1}^{F}\left(s_{g}\right)}{w\left(s_{g}\right)}\right)=\left(1-\underline{\theta}^{F}\right) \frac{P_{1}^{F}\left(s_{g}\right)}{w\left(s_{g}\right)} .
$$

It can be further simplified to

$$
P_{1}^{F}\left(s_{g}\right)-P_{1}^{F}\left(s_{g}\right)\left(1+w\left(s_{g}\right)\right)+\underline{\theta}^{F} w\left(s_{g}\right)=0 .
$$

Since $\underline{\theta}^{F}=\bar{m}-P_{1}^{F}\left(s_{g}\right), P_{1}^{F}\left(s_{g}\right)$ solves the following quadratic equation

$$
P_{1}^{F}\left(s_{g}\right)-P_{1}^{F}\left(s_{g}\right)\left(1+2 w\left(s_{g}\right)\right)+\bar{m} w\left(s_{g}\right)=0 .
$$

Equation (10) becomes

$$
\left(\underline{\theta}^{F}-P_{1}^{F}\left(s_{b}\right)\right)\left(1-\frac{P_{1}^{F}\left(s_{b}\right)}{w\left(s_{b}\right)}\right)=\left(1-\underline{\theta}^{F}\right) \frac{P_{1}^{F}\left(s_{b}\right)}{w\left(s_{b}\right)} .
$$

Thus, $P_{1}^{F}\left(s_{b}\right)$ solves

$$
P_{1}^{F}\left(s_{b}\right)-P_{1}^{F}\left(s_{b}\right)\left(1+w\left(s_{b}\right)\right)+\underline{\theta}^{F} w\left(s_{b}\right)=0 .
$$

Solving the system of the two quadratic equations (14)-(15) yields the following proposition.

Proposition 4 When $\theta$ and $l$ are uniformly distributed on $[0,1]$, in an equilibrium with FRM contracts home prices at $t=1$ are given by

$$
\begin{aligned}
& P_{1}^{F}\left(s_{g}\right)=\frac{1}{2}\left[1+2 w\left(s_{g}\right)-\sqrt{\left(1+2 w\left(s_{g}\right)\right)^{2}-4 \bar{m} w\left(s_{g}\right)}\right] \\
& P_{1}^{F}\left(s_{b}\right)=\frac{1}{2}\left[1+w\left(s_{b}\right)-\sqrt{\left(1+w\left(s_{b}\right)\right)^{2}-4\left(\bar{m}-P_{1}^{F}\left(s_{g}\right)\right) w\left(s_{b}\right)}\right] .
\end{aligned}
$$

\subsection{Cost of credit and the housing boom and bust cycle}

In this subsection we show that a decline in the cost of mortgage $\bar{m}$ can lead to a boom and bust cycle in the housing market. We start with the following observation.

Proposition 5 The homeownership rate $1-F\left(\underline{\theta}^{F}\right)$ is decreasing and home prices $P_{1}^{F}\left(s_{g}\right)$ and $P_{1}^{F}\left(s_{b}\right)$ at time $t=1$ are increasing in the mortgage payment $\bar{m}$.

Proof is in Appendix 
While it may seem surprising that home prices at time $t=1$ increase in the mortgage payment, the explanation of Proposition 5 is straightforward. Higher mortgage payments make homeownership less attractive, which reduces the homeownership rate. A lower housing supply in the secondary market at time $t=1$ translates into higher home prices.

To keep things simple, we have assumed a constant return to scale technology of home building. However, it is straightforward to introduce convex construction costs in our model. ${ }^{15}$ Proposition 5 says that cheaper mortgage loans lead to a higher homeownership rate and lower home prices at time $t=1$. With convex construction costs, cheaper credit would also increase home prices at time $t=0$, exacerbating a boom and bust cycle in the housing market in the case a "bad" economic state is realized.

Cheaper mortgage credit could be a result of government interest rate policies and implicit subsidies to too-big-too-fail financial institutions and government sponsored enterprises, such as Fannie Mae and Freddie Mac. It could be also caused by financial innovations, such as securitization, and by technological progress, such as computers and the Internet. No matter what causes it, our model shows that a decline in mortgage rates resulting in a construction boom and high initial home prices can contribute to a subsequent decline in home values. We note that this pattern broadly matches a recent housing market episode where a reduction of cost of credit and a construction boom prior to the Great Recession was followed by a subsequent decline in house prices.

\subsection{FRM modification}

In this section, we consider the possibility of reducing the FRM payment in the bad state of the economy, which was not anticipated by the borrowers and lenders at time zero. Specifically, at time $t=0+$ after the bad state $s_{b}$ is realized, but before borrowers default, a lender can unilaterally reduce mortgage payments. This mortgage modification will affect all his borrowers, because the lender cannot identify defaulters without knowing borrowers' wage shocks $l$ and housing utility $\theta$. We assume that mortgage modification is happening on a small scale and thus has no effect on the equilibrium home price $P_{1}^{F}\left(s_{b}\right)$.

We need the following condition for Theorem 1.

\footnotetext{
${ }^{15}$ We should expect convex construction costs in areas with limited land supply, or when construction happens at a high pace.
} 
Condition 1 Distribution functions $G$ and $F$ are such that $\frac{1-G(x)}{g(x)}$ and $\frac{1-F(x)}{f(x)}$ are decreasing in $x$.

We note that uniform distribution functions satisfy Condition 1 . We also note that this is a rather strong condition that can be potentially relaxed. For example, for the proof of Theorem 1, we need $G$ and $F$ to satisfy Condition 1 only in some neighborhoods of $\frac{\bar{m}}{w\left(s_{b}\right)}$ and $\hat{\theta}^{F}$ respectively.

Theorem 1 Assume Condition 1 holds. When wages $w_{b}$ in the bad state are low compared to mortgage payments $\bar{m}$, then FRM modification is Pareto improving, i.e., the lender can increase the revenue by lowering mortgage payment in the bad state. When wages $w_{b}$ in the bad state are high compared to mortgage payments $\bar{m}$, then lowering mortgage payment in the bad state reduces the lender's payoff, and the equilibrium mortgage is renegotiation-proof.

\section{Proof is in Appendix.}

Theorem 1 is very intuitive. A reduction in the mortgage payment in the bad state will reduce both strategic and liquidity defaults, which can benefit the lender. However, when wages in the bad state $w\left(s_{b}\right)$ are high compared to mortgage payments $\bar{m}$, most borrowers are solvent. As a result, a reduction in the default rate will not be enough to offset the loss of revenue from the solvent borrowers. In this case, the mortgage modification does not benefit the lender. On the other hand, when wages in the bad state $w\left(s_{b}\right)$ are low compared to mortgage payments $\bar{m}$, many borrowers are insolvent. In this case, the mortgage modification leads to a significant reduction in the number of defaults, which increases the lender's payoff.

Since the mortgage payment $\bar{m}$ is directly related to the home price $P_{0}$ at time zero, one can interpret Theorem 1 as follows. When wages in the bad state $w_{b}$ are low compared to the home price $P_{0}$ at time zero, then FRM modification is Pareto improving in the bad state. On the other hand, when wages in the bad state $w_{b}$ are high compared to the home price $P_{0}$ at time zero, then the FRM mortgage is renegotiation-proof.

Theorem 1 assumes the ex-post contract changes that are unanticipated by the borrowers and lenders at time zero. In the next section we consider a general space of contracts that allows for state-contingent mortgage repayments and study their impact on the market equilibrium. 


\section{Optimal Mortgage with Known Homeownership Values}

In this section, as an intermediate step towards the equilibrium with state-contingent mortgage contracts, we consider a setting in which the lender offers the borrower a state-contingent mortgage contract knowing the borrower's homeownership utility $\theta_{i}$ is sufficiently high, so that the borrower will not default strategically in any state. The borrower has to pay an amount $m(s)$ in state $s$. If the borrower fails to pay this amount the home is foreclosed by the lender. For the purpose of this section, we assume that home prices $P_{1}(s)$ are exogenous, and $P_{1}\left(s_{g}\right)>P_{1}\left(s_{b}\right) .{ }^{16}$

Since the borrower does not default strategically, his expected utility in state $s$ is given by

$$
v(s, \theta)=w(s) L+\left[1-G\left(\frac{m(s)}{w(s)}\right)\right](2 \theta-m(s))+\left[G\left(\frac{m(s)}{w(s)}\right)-G\left(\frac{P_{1}(s)}{w(s)}\right)\right]\left(\theta-P_{1}(s)\right),
$$

where the first term is the borrower's expected income, the second term represents the homeownership utility if he pays the mortgage, and the last term represents the housing utility in the second period when the borrower defaults at time $t=0+$ and buys a house at time $t=1$.

The optimal mortgage contract maximizes the borrower's expected utility

$$
\max _{m(s)} \pi_{g} v\left(s_{g}, \theta\right)+\pi_{b} v\left(s_{b}, \theta\right)
$$

subject to the lender's break even condition:

$$
P_{0} \bar{R}=\pi_{g} \Pi\left(s_{g}, m\left(s_{g}\right)\right)+\pi_{b} \Pi\left(s_{b}, m\left(s_{b}\right)\right) .
$$

Combining equations (17) with (18a) (see the proof of Theorem 2 in Appendix for details) allows us to rewrite the optimal contracting problem as

$$
\min _{m(s)} \pi_{g} G\left(\frac{m\left(s_{g}\right)}{w\left(s_{g}\right)}\right)+\pi_{b} G\left(\frac{m\left(s_{b}\right)}{w\left(s_{b}\right)}\right)
$$

subject to (18a). Thus, when the borrower does not default strategically, an optimal contract is the contract that minimizes the overall probability of liquidity default subject to the lender's break even condition.

\footnotetext{
${ }^{16}$ According to Proposition 6 in the next section, equilibrium home prices are always higher in the good state.
} 
Let

$$
Q(s, m(s))=\frac{w(s)}{g\left(\frac{m(s)}{w(s)}\right)}\left(1-G\left(\frac{m(s)}{w(s)}\right)\right)-\left(m(s)-P_{1}(s)\right)
$$

The optimal state-contingent mortgage contract for borrowers with high homeownership values is given by Theorem 2 .

Theorem 2 Let $\left\{\tilde{m}\left(s_{g}\right), \tilde{m}\left(s_{b}\right)\right\}$ satisfy

$$
Q\left(s_{g}, \tilde{m}\left(s_{g}\right)\right)=Q\left(s_{b}, \tilde{m}\left(s_{b}\right)\right)
$$

and the lender's break even condition (18a). Then $\left\{\tilde{m}\left(s_{g}\right), \tilde{m}\left(s_{b}\right)\right\}$ is the optimal contract for all borrowers with known $\theta \geq \tilde{\theta}$, where $\tilde{\theta}=\max _{s}\left[\tilde{m}(s)-P_{1}(s)\right]$.

Moreover, if the distribution function $G$ satisfies Condition 1, then

$$
\frac{\tilde{m}\left(s_{g}\right)}{w\left(s_{g}\right)}>\frac{\tilde{m}\left(s_{b}\right)}{w\left(s_{b}\right)}
$$

which implies that the required mortgage repayment is higher in the good state.

In the uniform example, equation (20) becomes

$$
\tilde{m}\left(s_{g}\right)-\tilde{m}\left(s_{b}\right)=\frac{1}{2}\left[w\left(s_{g}\right)-w\left(s_{b}\right)\right]+\frac{1}{2}\left[P_{1}\left(s_{g}\right)-P_{1}\left(s_{b}\right)\right]
$$

Proof is in Appendix.

Theorem 2 says that the optimal contract for borrowers with high homeownership values balances probabilities of liquidity default, which are determined by the wages $w(s)$ and the recovery values $P_{1}(s)$. Equation $(21)$ is very intuitive. It is optimal to set $\tilde{m}\left(s_{g}\right)>\tilde{m}\left(s_{b}\right)$ when $w\left(s_{g}\right)>w\left(s_{b}\right)$ and $P_{1}\left(s_{g}\right)>P_{1}\left(s_{b}\right)$. Indeed, when $w\left(s_{g}\right)>w\left(s_{b}\right)$, a higher payment in the good state reduces overall chances of default. In addition, when $P_{1}\left(s_{g}\right)>P_{1}\left(s_{b}\right)$, default is less costly to the lender in the good state due to the higher collateral value, which benefits the borrower in the form of lower mortgage payments.

\section{General Equilibrium with State-Contingent Mortgage Contracts}

In this section, we assume that lenders can offer any state-contingent mortgage contracts $m(s)$. A borrower has to pay $m(s)$ in state $s$, or he loses his home to the lender who would sell it at 
time $t=1$. Lenders do not know borrowers' homeownership values $\theta$, and the home prices are endogenous. FRM is a special case of a state-contingent mortgage contract.

\subsection{Equilibrium with a single state-contingent mortgage contract}

We start our equilibrium analysis assuming that there is only one type of state-contingent mortgage contract, i.e., all borrowers have to pay $m\left(s_{g}\right)$ and $m\left(s_{b}\right)$ in the good and bad states correspondingly. We are not making any assumptions about what payments $m\left(s_{g}\right)$ and $m\left(s_{b}\right)$ should be, other than they should satisfy the lender's break even condition. In this subsection, lenders are not allowed to offer other mortgage contracts.

We will use superscript $S$ to denote key variables in an equilibrium with a state-contingent mortgage. The definition of equilibrium with a single state-contingent mortgage is similar to that in the case with an FRM contract with the only change being that mortgage payments can be state-contingent.

Definition 2 An equilibrium with a single state-contingent mortgage contract consists of allocation of capital $K^{H}$ and $K$ into housing and production sectors, mortgage payments $m(s)$ and prices $\left\{w(s), R(s), P_{0}^{S}, P_{1}^{S}(s)\right\}$, such that taking the equilibrium prices and mortgage payments as given, the following is true.

At time $t=0$, i.e., before aggregate and idiosyncratic shocks $s$ and $l$ are known:

(i) Capitalists expect the same return on their investments in housing and production sectors,

(ii) Households buy homes if and only if homeownership results in strictly higher expected utility compared to renting in period one,

(iii) The housing market clears at time $t=0$, i.e., all homes built by capitalists are bought by households.

At time $t=0+$, i.e., when aggregate and idiosyncratic shocks $s$ and $l$ are revealed:

(iv) Homeowners with income less than $m(s)$ default for liquidity reason,

(v) Homeowners with income greater than $m(s)$ default strategically if and only if default increases their utility.

At time $t=1$, i.e., after economic shocks are fully absorbed by the economy:

(vi) Homeowners with housing utility less than $P_{1}^{S}(s)$ sell their homes in state $s$, 
(vii) Renters including those who defaulted at time $t=0+$ buy homes in state $s$ if their housing utility and their income are greater than $P_{1}^{S}(s)$,

(viii) Housing market clears at time $t=1$, i.e., no homes are left unoccupied in the second period.

It is straightforward to adjust the argument of Section 3 to the setting with a state-contingent mortgage. Let $\underline{\theta}^{S}$ denote the housing utility of the marginal homebuyer who is indifferent between buying and renting at $t=0$ under the state-contingent mortgage contract $m(s)$. As in the FRM equilibrium, home prices $P_{1}^{S}(s)$ at time $t=1$ must be such that $P_{1}^{S}(s)<\underline{\theta}^{S}$, otherwise the housing market would not clear due to the lack of home buyers. In addition, $P_{1}^{S}(s)<\underline{\theta}^{S}$ means that households who defaults at $t=0$ would buy homes again at time $t=1$ if they can afford them.

Similar to the FRM setting, households with housing utility $\theta \in\left(\underline{\theta}^{S}, m(s)-P_{1}^{S}(s)\right)$ strategically default in state $s$ at $t=0+$. However, in the setting with a state-contingent mortgage strategic default may occur in either state depending on the mortgage payments $m\left(s_{g}\right)$ and $m\left(s_{b}\right)$. Let's define $\hat{s}$ as the state in which strategic default occurs, i.e.,

$$
\hat{s}=\arg \max _{s}\left\{m(s)-P_{1}^{S}(s)\right\}
$$

and $\hat{s}^{-}$as the other state, i.e., the state in which strategic default does not happen.

We note that strategic default cannot happen in both states since it would mean that homebuyers who default strategically in both states are not better off than renters. The marginal homebuyer's housing utility is given by

$$
\underline{\theta}^{S}=m\left(\hat{s}^{-}\right)-P_{1}^{S}\left(\hat{s}^{-}\right)
$$

Indeed, a worker with $\underline{\theta}^{S}$ defaults strategically in state $\hat{s}$, and is indifferent between defaulting and paying the mortgage in state $\hat{s}^{-}$.

Workers with housing utility $\theta \in\left(\underline{\theta}^{S}, \hat{\theta}^{S}\right)$ strategically default in state $\hat{s}$ at $t=0+$, where

$$
\hat{\theta}^{S}=m(\hat{s})-P_{1}^{S}(\hat{s})
$$

Finally, one can verify that the housing market clearing conditions will have the same functional form for a given $\underline{\theta}^{S}$ and $m(s)$ as in the FRM equilibrium. The proposition below summarizes this 
discussion.

Proposition 6 An equilibrium with a single state-contingent mortgage contract $m(s)$ is characterized by the state

$$
\hat{s}=\arg \max _{s}\left\{m(s)-P_{1}^{S}(s)\right\}
$$

in which strategic default occurs at $t=0+$, and two thresholds of $\theta$ :

$$
\begin{aligned}
\hat{\theta}^{S} & =m(\hat{s})-P_{1}^{S}(\hat{s}), \\
\underline{\theta}^{S} & =m\left(\hat{s}^{-}\right)-P_{1}^{S}\left(\hat{s}^{-}\right) .
\end{aligned}
$$

At time $t=0,\left(1-F\left(\underline{\theta}^{S}\right)\right)$ homes are built, and the price of one home is $P_{0}=q$. Workers with $\theta \leq \underline{\theta}^{S}$ become renters, while workers with $\theta>\underline{\theta}^{S}$ take the state-contingent mortgages and buy homes.

At time $t=0+$ workers with $\underline{\theta}^{S}<\theta<\hat{\theta}^{S}$ strategically default.

At time $t=1$ only foreclosed homes are offered for sale and home prices $P_{1}^{S}(s)$ satisfy

$$
\begin{aligned}
& \left(F\left(\underline{\theta}^{S}\right)-F\left(P_{1}^{S}\left(s_{g}\right)\right)\right)\left(1-G\left(\frac{P_{1}^{S}\left(s_{g}\right)}{w\left(s_{g}\right)}\right)\right)=\left(1-F\left(\underline{\theta}^{S}\right)\right) G\left(\frac{P_{1}^{S}\left(s_{g}\right)}{w\left(s_{g}\right)}\right), \\
& \left(F\left(\underline{\theta}^{S}\right)-F\left(P_{1}^{S}\left(s_{b}\right)\right)\right)\left(1-G\left(\frac{P_{1}^{S}\left(s_{b}\right)}{w\left(s_{b}\right)}\right)\right)=\left(1-F\left(\underline{\theta}^{S}\right)\right) G\left(\frac{P_{1}^{S}\left(s_{b}\right)}{w\left(s_{b}\right)}\right) .
\end{aligned}
$$

The home prices are always higher in the good state:

$$
P_{1}^{S}\left(s_{g}\right)>P_{1}^{S}\left(s_{b}\right)
$$

Proof of equation (22) is analogous to the proof of equation (8a).

It may be surprising that home prices are always higher in the good state no matter what mortgage payments are. Indeed, mortgage payments determine default rates at time $t=0+$. However, people who defaulted at $t=0+$ reenter the housing market at time $t=1$. As a result, home prices at time $t=1$ are determined by the homeownership rate $\underline{\theta}^{S}$, which is the same in both state, and the purchasing power of the population, which is higher in the good state since $w\left(s_{g}\right)>w\left(s_{b}\right)$. Thus, $P_{1}^{S}\left(s_{g}\right)>P_{1}^{S}\left(s_{b}\right)$.

Proposition 6 says that a state contingent mortgage contract $m(s)$ comes with a strategic default option, which is valuable for borrowers with $\theta \in\left(\underline{\theta}^{S}, \hat{\theta}^{S}\right)$. The only contract that eliminates the 
strategic default option is the one for which $\underline{\theta}^{S}=\hat{\theta}^{S}$, i.e., the difference in mortgage payments is equal to the difference in the home prices:

$$
m^{*}\left(s_{g}\right)-m^{*}\left(s_{b}\right)=P_{1}\left(s_{g}\right)-P_{1}\left(s_{b}\right)
$$

This mortgage insures borrowers against uncertainty in home values. We call a mortgage $m^{*}$ that satisfies (23) a home equity insurance mortgage, or HEIM.

We note that the HEIM contract is quite close to the pass-through home equity insurance contract proposed by Shiller and Weiss (1999) and to continuous workout mortgages advocated by Shiller (2008).

Applying Proposition 6 to the home equity insurance mortgage yields the following corollary.

Corollary 1 The housing equilibrium with the home equity insurance mortgage contracts $m^{*}$ is characterized by the single threshold

$$
\theta^{*}=m^{*}\left(s_{g}\right)-P_{1}^{*}\left(s_{g}\right)=m^{*}\left(s_{b}\right)-P_{1}^{*}\left(s_{b}\right) .
$$

At time $t=0,1-F\left(\theta^{*}\right)$ homes are built and the price of one home is $P_{0}=q$. Workers with $\theta<\theta^{*}$ become renters, while workers with $\theta \geq \theta^{*}$ take the home equity insurance mortgages and buy homes. No strategic defaults occur in either state of the economy.

At time $t=1$ only homes foreclosed due to liquidity defaults are offered for sale and the home price $P_{1}^{*}(s)$ in state $s \in\left\{s_{g}, s_{b}\right\}$ satisfies

$$
\left(F\left(\theta^{*}\right)-F\left(P_{1}^{*}(s)\right)\right)\left(1-G\left(\frac{P_{1}^{*}(s)}{w(s)}\right)\right)=\left(1-F\left(\theta^{*}\right)\right) G\left(\frac{P_{1}^{*}(s)}{w(s)}\right) .
$$

When $\theta$ and $l$ are uniformly distributed on $[0,1]$, the home prices at $t=1$ are given by

$$
P_{1}^{*}(s)=\frac{1}{2}\left[1+2 w(s)-\sqrt{(1+2 w(s))^{2}-4 m^{*}(s) w(s)}\right]
$$

\subsection{A home equity insurance mortgage as the equilibrium mortgage contract}

In this subsection, we analyze an equilibrium in which competitive lenders can offer any mortgage contract to borrowers. Borrowers choose mortgage contracts that maximize their expected utility. In an equilibrium, lenders break even on the equilibrium mortgages, and cannot make a positive 
profit on any off-equilibrium mortgage contract. Below is the formal definition of the equilibrium.

Definition 3 An equilibrium in the housing and mortgage markets with no restrictions on mortgage design consists of allocation of capital $K^{H}$ and $K$ into housing and production sectors, a set of mortgage contract $\left\{m^{j}\right\}$ and prices $\left\{w(s), R(s), P_{0}^{*}, P_{1}^{*}(s)\right\}$, such that taking the equilibrium prices and mortgage contracts as given, the following is true.

At time $t=0$, i.e., before aggregate and idiosyncratic shocks $s$ and $l$ are known:

(i) The expected return on every equilibrium mortgage contract is equal to $\bar{R}$, and there exists no mortgage contract resulting in a strictly expected return for a capitalist,

(ii) Workers buy homes if and only if homeownership results in strictly higher expected utility compared to renting in period one,

(iii) Each homebuyer chooses a mortgage contract that maximizes his expected utility,

(iv) The housing market clears at time $t=0$, i.e., all homes built by capitalists are bought by households.

At time $t=0+$, i.e., when aggregate and idiosyncratic shocks $s$ and $l$ are revealed:

(v) Homeowners who have mortgage $m^{j}$ default for liquidity reason if their income is less than $m^{j}(s)$,

(vi) Homeowners who have mortgage $m^{j}$ and income greater than $m^{j}(s)$ default strategically if and only if default increases their utility.

At time $t=1$, i.e., after economic shocks are fully absorbed by the economy:

(vii) Homeowners with housing utility less than $P_{1}^{*}(s)$ sell their homes in state $s$,

(viii) Renters including those who defaulted at time $t=0+$ buy homes in state $s$ if their housing utility and their income are greater than $P_{1}^{*}(s)$,

(ix) Housing market clears at time $t=1$, i.e., no homes are left unoccupied in the second period.

A key insight of this section is to show that no mortgage contract that comes with a strategic default option can survive in an equilibrium. It follows from the observation that a strategic defaulter cares only about the mortgage payment in the state in which he does not default strategically. Indeed, if a borrower defaults strategically in state $\hat{s}$, his payoff does not depend on the mortgage payment in this state. As a result, a lender can lose strategic defaulters by slightly increasing the mortgage payment in state $\hat{s}^{-}$and lowering the mortgage payment in state $\hat{s}$. Since 
strategic defaults are costly for the lender, such a modification of a mortgage contract will increase the lender's expected payoff compared to the original mortgage.

More formally, suppose lenders break even on a mortgage contract $m^{\prime}$, and a positive mass of borrowers strategically defaults under this contract in state $\hat{s}$. This means that a lender loses money on a borrower with low $\theta$, who strategically defaults, and makes a strictly positive profit on a borrower with high $\theta$, who does not default strategically. A lender can offer a new contract $m^{\prime \prime}$ :

$$
\begin{aligned}
m^{\prime \prime}\left(\hat{s}^{-}\right) & =m^{\prime}\left(\hat{s}^{-}\right)+\varepsilon^{-} \\
m^{\prime \prime}(\hat{s}) & =m^{\prime}(\hat{s})-\varepsilon,
\end{aligned}
$$

with $\varepsilon>0$ and $\varepsilon^{-}>0$, such that borrowers who do not strategically default under contract $m^{\prime}$ are weakly better off under contract $m^{\prime \prime}$. Since $\varepsilon$ and $\varepsilon^{-}$can be made arbitrarily small, the lender will keep making a strictly positive profit on these borrowers. On the other hand, the strategic defaulters would strictly prefer mortgage $m^{\prime}$ over $m^{\prime \prime}$, since only the mortgage payment in the state $\hat{s}^{-}$, in which they do not default strategically, matters to them. As a result, the lender will stop losing money on them under contract $m^{\prime \prime}$. Thus, the lender will make a strictly positive profit with contract $m^{\prime \prime}$.

The above argument shows that a mortgage with a strategic default option cannot be an equilibrium contract. Consequently, only a home equity insurance mortgage can be an equilibrium mortgage contract.

Theorem 3 If there is an equilibrium with state contingent mortgage contracts, then an equilibrium contract $m^{*}$ takes the form of a home equity insurance mortgage:

$$
m^{*}\left(s_{g}\right)-m^{*}\left(s_{b}\right)=P_{1}^{*}\left(s_{g}\right)-P_{1}^{*}\left(s_{b}\right),
$$

and the housing equilibrium is characterized by Corollary 1.

Proof is in Appendix.

We will refer to an equilibrium with a HEIM contract as the HEIM equilibrium. 


\subsection{Existence of an equilibrium with state-contingent mortgage contracts}

Theorem 3 establishes that HEIM is the only mortgage contract that can exist in equilibrium, but does not guarantee the existence of the equilibrium. If a HEIM equilibrium exists, then it must be impossible for a lender to make a positive profit by offering a non-HEIM mortgage contract.

Let's consider an arbitrary mortgage $m$. We assume that the mortgage is offered on a small scale, and it does not change the HEIM equilibrium prices $P_{1}^{*}\left(s_{g}\right)$ and $P_{1}^{*}\left(s_{b}\right)$. If a borrower with $\theta \in(\underline{\theta}, \hat{\theta})$ takes this mortgage he will strategically default in state $\hat{s}$, where

$$
\begin{aligned}
\hat{s} & =\arg \max _{s}\left\{m(s)-P_{1}^{*}(s)\right\}, \\
\hat{s}^{-} & =\arg \min _{s}\left\{m(s)-P_{1}^{*}(s)\right\} \\
\hat{\theta} & =m(\hat{s})-P_{1}^{*}(\hat{s}), \\
\underline{\theta} & =m\left(\hat{s}^{-}\right)-P_{1}^{*}\left(\hat{s}^{-}\right) .
\end{aligned}
$$

Let $z$ and $z^{*}$ denote the probabilities ${ }^{17}$ that a borrower does not default for liquidity reasons under mortgages $m$ and $m^{*}$ :

$$
\begin{aligned}
z & =\pi_{g}\left(1-G\left(\frac{m\left(s_{g}\right)}{w\left(s_{g}\right)}\right)\right)+\pi_{b}\left(1-G\left(\frac{m\left(s_{b}\right)}{w\left(s_{b}\right)}\right)\right), \\
z^{*} & =\pi_{g}\left(1-G\left(\frac{m^{*}\left(s_{g}\right)}{w\left(s_{g}\right)}\right)\right)+\pi_{b}\left(1-G\left(\frac{m^{*}\left(s_{b}\right)}{w\left(s_{b}\right)}\right)\right) .
\end{aligned}
$$

To make a positive profit on mortgage $m$, the lender must transfer costs associated with strategic defaults on borrowers with $\theta \geq \hat{\theta}$. Those borrowers could still choose contract $m$ over $m^{*}$ but only if they have a better chance of remaining homeowners under mortgage $m$, i.e., when $z>z^{*}$. If $z \leq z^{*}$, only strategic defaulters would choose $m$, and the lender would lose money on it.

The following Lemma shows that borrowers' preferences over the mortgage contracts are determined by their homeownership values.

Lemma 1 When $z>z^{*}$, borrowers with $\theta \in\left(\theta^{1}, \theta^{2}\right)$ choose mortgage $m^{*}$ over mortgage $m$, while

\footnotetext{
${ }^{17} z$ and $z^{*}$ are functions of the mortgage payments. We omit the arguments to simplify the notation.
} 
borrowers with $\theta \in\left(\underline{\theta}, \theta^{1}\right) \cup\left(\theta^{2}, \bar{\theta}\right)$ choose $m$ over $m^{*}$, where

$$
\begin{aligned}
& \theta^{1}=\min \left\{\hat{\theta}, \frac{z^{*} \theta^{*}-\pi_{\hat{s}^{-}}\left(1-G\left(\frac{m\left(\hat{s}^{-}\right)}{w\left(\hat{s}^{-}\right)}\right)\right) \underline{\theta}}{z^{*}-\pi_{\hat{s}^{-}}\left(1-G\left(\frac{m\left(\hat{s}^{-}\right)}{w\left(\hat{s}^{-}\right)}\right)\right)}\right\}, \\
& \theta^{2}=\max \left\{\hat{\theta}, \frac{z \underline{\theta}-z^{*} \theta^{*}+\pi_{\hat{s}}\left(1-G\left(\frac{m(\hat{s})}{w(\hat{s})}\right)\right)(\hat{\theta}-\underline{\theta})}{z-z^{*}}\right\} .
\end{aligned}
$$

Borrowers with $\theta \in\left(\underline{\theta}, \theta^{1}\right)$ strategically default in state $\hat{s}$.

Proof is in Appendix.

Intuitively, borrowers with high homeownership values $\left(\theta^{2}, \bar{\theta}\right)$ prefer $m$, because it improves their chance to enjoy homeownership utility when $z>z^{*}$. Borrowers with intermediate homeownership values $\left(\theta^{1}, \theta^{2}\right)$ do not like $m$, because it is more expensive than $m^{*}$ due to costs imposed by strategic defaults. Borrowers with low homeownership values $\left(\underline{\theta}, \theta^{1}\right)$ prefer $m$, because they take advantage of the strategic default option.

We note that

$$
\underline{\theta}<\theta^{*}<\theta^{1} \leq \hat{\theta} \leq \theta^{2} \leq \bar{\theta}
$$

whenever $m \neq m^{*}$.

Lemma 1 implies that the probability of a strategic default in state $\hat{s}$ under mortgage $m$ is equal to

$$
\xi\left(m\left(s_{g}\right), m\left(s_{b}\right)\right)=\frac{F\left(\theta^{1}\right)-F(\underline{\theta})}{1-F(\underline{\theta})-\left(F\left(\theta^{2}\right)-F\left(\theta^{1}\right)\right)} .
$$

One can see that $\xi\left(m^{*}\left(s_{g}\right), m^{*}\left(s_{b}\right)\right)=0$ and $\xi\left(m\left(s_{g}\right), m\left(s_{b}\right)\right)>0$ whenever $m \neq m^{*}$.

The following Theorem characterizes the existence of an equilibrium with state-contingent mortgage contracts.

Theorem 4 If a HEIM contract is a solution to the following problem:

$$
\max _{m\left(s_{g}\right), m\left(s_{b}\right)} \pi_{\hat{s}^{-}}\left(1-G\left(\frac{m\left(\hat{s}^{-}\right)}{w\left(\hat{s}^{-}\right)}\right)\right) \underline{\theta}+\pi_{\hat{s}}\left(1-G\left(\frac{m(\hat{s})}{w(\hat{s})}\right)\right)\left(1-\xi\left(m\left(s_{g}\right), m\left(s_{b}\right)\right)\right) \hat{\theta}
$$

then the HEIM equilibrium is the unique equilibrium. Otherwise, there is no equilibrium with statecontingent mortgage contracts.

Proof is in Appendix. 
The objective function (27) represents the lender's payoff under mortgage $m$ without terms that do not depend on mortgage payments. If a HEIM contract maximizes this function, then the lender cannot make a positive profit on a different mortgage contract. In this case, the HEIM is the equilibrium contract and the equilibrium is unique.

If a non-HEIM mortgage maximizes (27), then there is a profitable deviation and the HEIM equilibrium unravels. According to the argument of Section 5.2, a non-HEIM mortgage cannot be sustained in an equilibrium either. Thus, there is no equilibrium with state-contingent mortgage contracts in this case.

The distribution of the homeownership values $F(\theta)$ is important for the existence of the equilibrium, as it determines the losses associated with the strategic defaults. When $f(\theta)$ is high in a neighborhood of $\theta^{*}$, then a deviation from the HEIM contract becomes too costly due to the large mass $\left(F\left(\theta^{1}\right)-F(\underline{\theta})\right)$ of strategic defaulters, and the HEIM equilibrium exists. On the other hand, when $f(\theta)$ is low in a neighborhood of $\theta^{*}$, the HEIM equilibrium may unravel, since the low mass $\left(F\left(\theta^{1}\right)-F(\underline{\theta})\right)$ of strategic defaulters may allow a profitable non-HEIM contract.

Wage levels in the two states are also important for equilibrium existence. When wages are much lower in the bad state than in the good state, the HEIM contract will result in much higher liquidity default rates in the bad state even though HEIM payments are already lower in the bad state. As a result, further lowering payments in the bad state and increasing them in the good state may lead to a profitable deviation from the HEIM contract, unraveling the HEIM equilibrium.

To sum up, the economic intuition suggests that the equilibrium is less likely to exist when there are fewer households with homeownership values close to that of the marginal homebuyer $\theta^{*}$, and when wages in the bad state are much lower than those in the good state. The following numerical examples confirm this intuition.

\subsubsection{Numerical analysis of the equilibrium existence problem}

To investigate the existence of equilibrium with state-contingent mortgage contracts, we solve the optimal deviation problem (27) numerically. The following table shows parameter values that we keep unchanged in all our examples below. ${ }^{18}$

\footnotetext{
${ }^{18}$ Since idiosyncratic labor productivity $l$ is distributed on the interval $[0,1]$, wage levels $w\left(s_{g}\right)$ and $w\left(s_{b}\right)$ are the highest possible labor incomes in the good and bad states respectively.
} 
Table 1: Parameter Values

\begin{tabular}{|l|l|}
\hline Parameter & Value \\
\hline Price of home at time zero, $P_{0}$ & 0.45 \\
\hline Probability of good state, $\pi_{g}$ & 0.5 \\
\hline Expected return on capital, $\bar{R}$ & 1.2 \\
\hline Idiosyncratic labor productivity pdf, $g(l)$ & 1, for $l \in[0,1]$ \\
\hline Wage level in good state, $w\left(s_{g}\right)$ & 3 \\
\hline
\end{tabular}

We consider two examples of probability density functions of homeownership value:

$$
\begin{aligned}
& f_{1}(\theta)=1, \text { for } \theta \in[0,1], \\
& f_{2}(\theta)=\left\{\begin{array}{c}
1.0421, \text { for } \theta \in[0,0.35) \\
0.2, \text { for } \theta \in[0.35,0.4] \\
1.0421, \text { for } \theta \in(0.4,1]
\end{array}\right.
\end{aligned}
$$

The main difference between these two examples is that the density of households with $\theta$ close to $\theta^{*}$ is five times higher in the first example, which corresponds to the uniform example, than in the second example.

We vary the wage level $w\left(s_{b}\right)$ from 1 to 3 , and find that the HEIM equilibrium always exists in the uniform example. However, in the second example, the HEIM equilibrium exists only for $w\left(s_{b}\right) \geq 1.5$. These findings are consistent with our earlier observation that the HEIM equilibrium may unravel when the density of strategic defaulters is low and when wages in the bad state are low.

Table 2 below shows parameter values in the HEIM equilibrium and solutions $\left(\dot{m}\left(s_{g}\right), \dot{m}\left(s_{b}\right)\right)$ to the optimal deviation problem $(27)$ for the two pdf functions when $w\left(s_{b}\right)=1.2$. It shows that the HEIM equilibrium exists in the uniform example, since the solution to the optimal deviation problem (27) is equal to the HEIM payments. However, the optimal deviation mortgage in Example 2 has a higher (lower) payment in the good (bad) state than the corresponding HEIM payment. As a result, Example 2 has no equilibrium with state-contingent mortgage contracts. 
Table 2: Numerical Examples

\begin{tabular}{|l|l|l|}
\hline Parameter & Example 1 & Example 2 \\
\hline Homeownership value pdf, $f(\theta)$ & $f_{1}$ & $f_{2}$ \\
\hline Wage level in bad state, $w\left(s_{b}\right)$ & 1.2 & 1.2 \\
\hline HEIM marginal homebuyer, $\theta^{*}$ & 0.359 & 0.361 \\
\hline HEIM payment in good state, $m^{*}\left(s_{g}\right)$ & 0.650 & 0.649 \\
\hline HEIM payment in bad state, $m^{*}\left(s_{b}\right)$ & 0.577 & 0.579 \\
\hline Optimal deviation in good state, $\dot{m}\left(s_{g}\right)$ & 0.650 & 0.658 \\
\hline Optimal deviation in bad state, $\dot{m}\left(s_{b}\right)$ & 0.577 & 0.568 \\
\hline Equilibrium exists & Yes & No \\
\hline
\end{tabular}

\section{Welfare Implications of Home Equity Insurance Mortgage Con- tracts}

The previous section has established that in the absence of restrictions on mortgage design the home equity insurance mortgage emerges as the equilibrium contract. In this section, we compare the equilibrium with the HEIM contract $m^{*}$ of Section 5 versus the equilibrium with the FRM contract $\bar{m}$ of Section 3. We start our analysis with the effect of mortgage design on home prices and homeownership rate.

Proposition 7 If in the good state the HEIM payment is higher (equal, lower) than the FRM payment the home prices in the HEIM equilibrium in both states are higher (equal, lower) than the corresponding prices in the FRM equilibrium. Moreover, the homeownership is lower (equal, higher) in the HEIM equilibrium compared to the FRM equilibrium:

$$
\begin{aligned}
& \text { if } m^{*}\left(s_{g}\right)>\bar{m}, \text { then } \theta^{*}>\underline{\theta}^{F} \& P_{1}^{*}(s)>P_{1}^{F}(s) \text { for } s \in\left\{s_{g}, s_{b}\right\}, \\
& \text { if } m^{*}\left(s_{g}\right)=\bar{m}, \text { then } \theta^{*}=\underline{\theta}^{F} \& P_{1}^{*}(s)=P_{1}^{F}(s) \text { for } s \in\left\{s_{g}, s_{b}\right\}, \\
& \text { if } m^{*}\left(s_{g}\right)<\bar{m}, \text { then } \theta^{*}<\underline{\theta}^{F} \& P_{1}^{*}(s)<P_{1}^{F}(s) \text { for } s \in\left\{s_{g}, s_{b}\right\},
\end{aligned}
$$


where the homeownership thresholds are given by

$$
\begin{aligned}
\underline{\theta}^{F} & =m^{F}\left(s_{g}\right)-P_{1}^{F}\left(s_{g}\right), \\
\theta^{*} & =m^{*}\left(s_{g}\right)-P_{1}^{*}\left(s_{g}\right)=m^{*}\left(s_{b}\right)-P_{1}^{*}\left(s_{b}\right) .
\end{aligned}
$$

Proof is in Appendix.

Proposition 7 shows that mortgage payments in the good state are the key determinant of the homeownership rate and the long-term home prices. When $m^{*}\left(s_{g}\right)>\bar{m}$, more homes are built in the FRM equilibrium. This is because the FRM contract attracts strategic defaulters with low homeownership values, who do not care about mortgage payments in the bad state. Higher housing inventories translate into lower home prices on the secondary market at time $t=1$.

On the other hand, when $m^{*}\left(s_{g}\right)<\bar{m}$, all homebuyers with the FRM mortgage would also buy homes with the HEIM mortgage. A higher homeownership rate associated with HEIM leads to lower home prices at time $t=1$.

It may seem counterintuitive that if $m^{*}\left(s_{g}\right)=\bar{m}$ the prices are the same in the bad state, even though there are more strategic and liquidity defaults under FRM contract. However, those who default at $t=0+$ buy their homes back at $t=1$ if their income is greater than the home price at $t=1$. Thus, the net effect of defaults at time $t=0+$ on housing demand and supply at $t=1$ is zero.

Theorem 5 If wages in the bad state are sufficiently low, then the equilibrium with home equity insurance mortgages Pareto dominates the equilibrium with fixed-rate mortgages. Specifically, the homeownership rate is higher, while the mortgage payments, default rates, and home prices are lower in both states in the HEIM equilibrium.

If wages in the bad state are not too low, then the homeownership rate is lower and prices are higher in both states with HEIMs compared to the equilibrium with FRMs. Households with low homeownership values $\theta \in\left(\underline{\theta}^{F}, \theta^{*}\right]$ are strictly worse off in the HEIM equilibrium, while households with higher homeownership values $\theta \geq \hat{\theta}^{F}$ are better off in the HEIM equilibrium.

Proof is in Appendix.

To understand Theorem 5, we recall that FRM contracts embed a strategic default option, which contributes positively to the homeownership rate. The home equity insurance mortgage eliminates the strategic default option with associated default inefficiencies. However, without this 
option, homeownership may become less attractive to some borrowers with relatively low $\theta$. As a result, it is possible that homeownership can be lower and these marginal borrowers are worse off in the HEIM equilibrium.

When wages are not too low in the bad state, the default rate is not that sensitive to a reduction in the mortgage payment associated with the HEIM contract. In order to compensate for the lower revenue in the bad state, the HEIM contract requires a higher than the FRM payment in the good state. This leads to a lower homeownership rate in the HEIM equilibrium. Consequently, workers with $\theta \in\left(\underline{\theta}^{F}, \theta^{*}\right]$ are better off in the FRM equilibrium, where they buy homes at time $t=0$ and enjoy homeownership utility in the first period in the good state, and strategically default in the bad state. On the other hand, borrowers with higher homeownership values $\left(\theta \geq \hat{\theta}^{F}\right)$ are worse off in the FRM equilibrium, since they end up cross-subsidizing the strategic defaulters.

When wages are sufficiently low in the bad state, the default rate is highly sensitive to a reduction in mortgage payments, and the FRM contract is very inefficient. As a result, it is possible to have the HEIM contract with lower than FRM payments in both states and break even. In this case, the HEIM equilibrium Pareto dominates the FRM equilibrium, since all homeowner are strictly better off with the HEIM contract and there are more of them.

\section{Robustness and Extensions}

In order to keep our analysis tractable and transparent, we have made a number of simplifying assumptions. This has allowed us to highlight several novel relationships among mortgage design, default decisions, home prices and the homeownership rate. We hope that our tractable framework could be helpful in future research on housing and mortgage markets. Below we discuss several potential extensions of our setting.

\subsection{Alternative production technologies}

For tractability we assumed a simple linear production function form (1). However, our key findings would be preserved in the environments with other production function forms. In particular, Theorem 3 establishing HEIM as the equilibrium contract form does not really depend on the shape of the production function.

We also note that other production functions can induce additional general equilibrium effects. 
For example with the Cobb-Douglas form $Y(K, L, s)=A(s) K^{\alpha} L^{1-\alpha}$ with $\alpha \in(0,1)$ if HEIMs increase the housing supply, the shift of capital towards the housing sector will result in higher equilibrium return to capital and lower wages compared to FRM equilibrium. While such effects would mute to some extent the effects of home equity insurance loans on the equilibrium homeownership rate and welfare of households, we expect that our key insights (including Theorem 5) would hold for more general production forms.

We also assumed that the construction of homes can only happen at time 0. However, if home construction is possible in the intermediate period, home prices would still be lower in the bad state relative to the good state. Intuitively, there will be no new home construction in the bad state as there is already excessive supply of homes build at time zero given the reduced purchasing power of the population. While new home construction can occur in the good state of the economy, it would not fully eliminate the relative difference in prices across states that drive our key results.

\subsection{Multiple credit categories}

For simplicity we assumed that all borrowers have the same expected income profiles. One can extend our model to a setting with multiple observable credit categories based on the expected income profiles of borrowers (e.g., subprime and prime). Our key insights would extend to such a setting as one could view our above analysis as characterizing the mortgage lending market in each of these credit categories. ${ }^{19}$ In such a setting, HEIMs would be particularly beneficial to borrowers with risky income profiles as these contracts reduce the inefficiencies caused by liquidity default. However, HEIM contracts can also benefit the safest borrowers by preventing strategic defaults and hence reducing the mortgage rates.

\subsection{Refinancing}

In our analysis we did not consider an option to refinance a mortgage. This additional option effectively makes FRM state-contingent as some borrowers could refinance their loans when market interest rates are low. However, it would not in general lead to similar outcomes to equilibrium with HEIMs. This is because the HEIM contract implies an automatic reduction in mortgage payments during the bad economic times while refinancing is conditional on borrower qualifying for better

\footnotetext{
${ }^{19}$ These submarkets will then be linked together by the equilibrium market clearing conditions and equilibrium factor returns.
} 
mortgage terms. As lower rates during the economic downturns are also associated with higher default premia due to declines in home values and borrower creditworthiness, some borrowers may not be able to reduce their mortgage payments through refinancing. This observation is consistent with the empirical evidence showing that during the Great Recession many borrowers were not able to refinance their mortgages despite historically low risk-free rates (see Agarwal et al. 2015).

\subsection{Risk aversion}

For tractability we have assumed a linear utility in consumption goods and focused on the effects of mortgage contracts on foreclosure inefficiencies. In a setting with borrower risk aversion, statecontingent lending contracts will provide additional benefits to households by partially insuring their labor income risk and hence allowing them to better smooth their consumption profiles. This additional benefit should increase the value of state-contingent contracts relative to fixed-rate mortgages.

We also assumed that capitalists are risk neutral. However, the ability of the financial sector to bear aggregate risk during economic downturns may be limited. ${ }^{20}$ As HEIMs require lower mortgage repayments in the bad state, this could make them costly to financial intermediaries. On the other hand, HEIMs may have a positive effect on risk averse lenders in some cases since HEIMs reduce liquidity defaults and eliminate strategic defaults in the bad economic state. These suggest that the HEIM effect on risk averse lenders can be ambiguous.

We also note that there are mechanisms such as securitization that could at least partly transfer aggregate risk away from the banking sector by allowing more wealthy households (capitalists) to hold the aggregate portfolio of mortgage debt and effectively insure the less wealthy (workers in our model). We expect that in such settings the equilibrium state-contingent mortgage contracts would still require lower repayments in states with lower home prices.

\subsection{Foreclosure externalities}

In our setting foreclosures generate deadweight losses because houses remain unoccupied for one period. The number of foreclosures however do not directly affect house prices in the secondary market as these are determined by the initial housing supply and the state of the economy with

\footnotetext{
${ }^{20}$ See recent work by Greenwald, Landvoigt, and Van Nieuwerburgh (2017), who explore the effect of sharedappreciation mortgages on financial intermediaries with limited risk-bearing capacity in the quantitative general equilibrium model.
} 
associated labor market conditions. ${ }^{21}$ There is no direct impact of foreclosures on house prices as borrowers who default can buy back their homes at time 1 and the foreclosures do not affect the quality of housing. In that sense, we could think about the equilibrium at time 1 as the longer term equilibrium when the markets fully absorb the shock.

We could capture the more immediate impact of a foreclosure crisis on equilibrium outcomes by introducing some additional costs of foreclosures. For example, we could assume that some borrowers who default on their mortgages are excluded from the housing market at time $1 .{ }^{22}$ This modification implies that foreclosures will have adverse impact on house prices by limiting the number of potential buyers at time 1 resulting in foreclosure externality. In an FRM equilibrium this will contribute to the larger spread between house prices across states, which would reinforce the value of state-contingent contracts.

\subsection{ARMs versus HEIMs}

The fundamental feature of the HEIM contract is its dependence on house price level which eliminates a strategic default option by fully insuring borrower's equity position against the movement in house prices. It happens that in our setting we can also implement this contract as a special form of an adjustable rate-mortgage. In particular consider an ARM contract with required payments equal to $m^{A R M}(r(s))=P_{0}[1+\gamma(r(s))]$ where $r(s)=R(s)-1$ and $\gamma$ is a non-decreasing function of $r(s)$ such that $m^{*}(s)=m^{A R M}(r(s))$ for all $s$. Such function $\gamma$ will exist in our setting as market interest rate and house prices co-move together across states with bad economic states being associated with a decline in house prices and market interest rates and vice versa.

We note however that such a function may be different from typical indexation forms used in the marketplace on ARM contracts. Nonetheless, if home prices, wages, and interest rates are sufficiently positively correlated our analysis suggests that even standard ARM contracts may be more efficient than FRMs, because lower payments in the bad state reduce expected liquidity and strategic defaults. This may also help justify a documented high concentration of ARMs among riskier borrowers (e.g, see Mayer et al. 2009 and Keys et al. 2013).

Recent empirical evidence is consistent with this observation. In particular, Keys, Piskorski, Seru, and Yao (2014) and Di Maggio et al. (2014, 2017) show that mortgage rate declines during

\footnotetext{
${ }^{21}$ However, the expected foreclosures in our setting indirectly affect prices at time 1 through their impact on mortgage rates, homeownership rate, and the housing supply.

${ }^{22}$ Alternatively. some borrowers who defaulted may lose interest in homewonership due to their adverse experience.
} 
the Great Recession due to ARM contracts resetting to a low rate had a direct positive impact on borrowers who experienced these reductions by reducing their default rate and increasing their consumption. Moreover, regions more exposed to mortgage rate declines due to ARM resets saw a relatively faster recovery in house prices, increased consumption, and decline in foreclosure rate. Overall, this evidence highlights the potential role of ARM contracts in insuring households against recessions if interest rate indices to which these loans are indexed are expected to be lower during economic downturns and higher during expansions.

\subsection{Non-Existence of Equilibrium}

Our findings in Section 5.3 indicate that unrestricted competition may lead in some cases to a collapse of mortgage market equilibrium. ${ }^{23}$ We note that prior literature established that in many types of insurance markets private information can lead to non-existence of market equilibrium when uninformed insurers can offer contracts that induce informed agents to self-select into insurance contracts (Rothschild and Stiglitz 1976). Our results naturally connect with this literature given that our setting recognizes the informational asymmetries in the mortgage market and the potential insurance role of state-contingent mortgage contracts.

We also note that in the case in which the equilibrium with state-contingent contracts does not exist it could be beneficial to impose some restrictions on contract terms. This observation highlights the potential understudied role of government sponsored enterprises (GSEs): by subsidizing a restricted contract choice the GSEs may help facilitate the existence of a stable mortgage market.

\section{Conclusion}

In this paper we develop a tractable general equilibrium framework of housing and mortgage markets with aggregate and idiosyncratic risks, costly liquidity and strategic defaults, empirically relevant informational asymmetries, and endogenous mortgage design. We show that the equilibrium contract takes the form of the home equity insurance mortgage that solves the adverse selection problem imposed by the strategic defaulters with low homeownership values. We also find that a widespread adoption of HEIM loans may have ambiguous effects on the homeownership rate and

\footnotetext{
${ }^{23}$ In this regard we note that the period preceding the recent crisis and the collapse of the private residential lending market was characterized by a significant growth in nontradtional mortgage products and a fierce competition among lenders (Keys et al. 2013).
} 
welfare of marginal homebuyers.

We note that while the HEIM contract is similar to some of the recent proposals (e.g., Shiller 2008) such mortgages have not yet been widely adopted in the marketplace. The widespread adoption of these loans would require the development of timely and accurate regional house price indices. $^{24}$ Alternatively, appropriately structured ARM contracts may share some of the benefits of the state-contingent mortgage contracts as long as the relevant interest rate indices to which these loans are indexed closely co-move with home prices and borrowers' income. In such settings rather than exposing borrowers to interest rate risk, ARMs can effectively provide households with valuable insurance against recessions by lowering mortgage payments in the states when wages and house prices are low. This observation suggests that in economies with high share of ARMs the monetary policy should take into account ARM's potential role as an automatic stabilizer.

Our tractable framework has the potential to be used to address a number of policy questions related to the design of mortgage contracts, mortgage market regulations, and the welfare implications of policy interventions during the housing crisis. In addition, one can incorporate nominal prices and interest rates in our setting to investigate the interplay between the central bank polices and mortgage and housing markets.

There are at least a couple of reasons why it may be optimal for the government to intervene in our setting. First, our results show that unrestricted competition between lenders may lead in some cases to a non-existence of equilibrium. In such cases, public policy may help facilitate the existence of a stable mortgage market by subsidizing a restricted set of contracts. Second, policy interventions could also be justified by the inability of market participants to fully internalize the impact of their actions on equilibrium outcomes. For example, in a setting with foreclosure externalities that we discussed in Section 7.5, it may be socially optimal to provide households with more insurance against housing downturns than the level implied by the private market equilibrium. We are currently exploring these questions in our ongoing research.

\footnotetext{
${ }^{24}$ Recent market developments related to the emergence of online data providers such as Zillow are promising in this regard. Hartman-Glaser and Hebert (2016) point out though that if there are informational asymmetries between borrowers and lenders about the ability of such indices to measure underlying aggregate states, the risk-sharing ability of state-contingent contracts based on such indices can be limited.
} 


\section{Appendix}

\section{Proof of Proposition 1}

Strategic default occurs if and only if a borrower obtains a higher utility from defaulting than paying the mortgage. According to (2) and (3), this happens when

$$
w(s) l_{i}+1_{w(s) l_{i} \geq P_{1}^{F}(s)} \max \left(0, \theta_{i}-P_{1}^{F}(s)\right)>w(s) l_{i}-\bar{m}+\theta_{i}+\max \left(\theta_{i}, P_{1}^{F}(s)\right),
$$

implying

$$
1_{w(s) l_{i} \geq P_{1}^{F}(s)} \max \left(0, \theta_{i}-P_{1}^{F}(s)\right)>\theta_{i}-\bar{m}+\max \left(\theta_{i}, P_{1}^{F}(s)\right) .
$$

There are two cases to consider.

Case 1: $\bar{m} \leq w(s) l_{i}<P_{1}^{F}(s)$, i.e., the borrower can pay the mortgage, but cannot afford to buy a home at time 1 . The above strategic default condition becomes

$$
\bar{m} \geq \theta_{i}+\max \left(\theta_{i}, P_{1}^{F}(s)\right) .
$$

This inequality contradicts the assumption that $\bar{m}<P_{1}^{F}(s)$ used to define Case 1. As a result, Case 1 is not relevant to our analysis.

Intuitively, the borrower would never default strategically when the house is worth more than the mortgage payment.

Case 2: $w(s) l_{i} \geq P_{1}^{F}(s)$, i.e., the borrower can buy a home at time 1 . The strategic default condition can be rewritten as follows

$$
\max \left(0, \theta_{i}-P_{1}^{F}(s)\right)>\theta_{i}-\bar{m}+\max \left(\theta_{i}-P_{1}^{F}(s), 0\right)+P_{1}^{F}(s)
$$

which simplifies to

$$
\bar{m}>\theta+P_{1}^{F}(s)
$$

\section{Proof of Proposition 3}

The following argument demonstrates that it is impossible to have $P_{1}^{F}\left(s^{*}\right) \geq P_{1}^{F}\left(s^{\prime}\right)$, and $w\left(s^{*}\right)<$ $w\left(s^{\prime}\right)$ at the same time. To see it suppose that by contradiction $w\left(s^{*}\right)<w\left(s^{\prime}\right)$ and $P_{1}^{F}\left(s^{*}\right) \geq P_{1}^{F}\left(s^{\prime}\right)$. 
From (6) and the fact that $\frac{P_{1}^{F}\left(s^{*}\right)}{w\left(s^{*}\right)}>\frac{P_{1}^{F}\left(s^{\prime}\right)}{w\left(s^{\prime}\right)}$ we get that

$$
\begin{gathered}
\left(F\left(\underline{\theta}^{F}\right)-F\left(P_{1}^{F}\left(s^{\prime}\right)\right)\right)\left(1-G\left(\frac{P_{1}^{F}\left(s^{\prime}\right)}{w\left(s^{\prime}\right)}\right)\right)> \\
\left(F\left(\underline{\theta}^{F}\right)-F\left(P_{1}^{F}\left(s^{*}\right)\right)\right)\left(1-G\left(\frac{P_{1}^{F}\left(s^{*}\right)}{w\left(s^{*}\right)}\right)\right)=\left(1-F\left(\underline{\theta}^{F}\right)\right) G\left(\frac{P_{1}^{F}\left(s^{*}\right)}{w\left(s^{*}\right)}\right) \\
>\left(1-F\left(\underline{\theta}^{F}\right)\right) G\left(\frac{P_{1}^{F}\left(s^{\prime}\right)}{w\left(s^{\prime}\right)}\right),
\end{gathered}
$$

which contradicts the market clearing condition (7). Thus, the home price must be higher in the state with higher wages, which proves $(8 \mathrm{a})$.

\section{Proof of Proposition 5}

Equations $(9),(10)$ that determine equilibrium prices $P_{1}^{F}\left(s_{g}\right), P_{1}^{F}\left(s_{b}\right)$ can be rewritten as

$$
\begin{aligned}
F\left(\bar{m}-P_{1}^{F}\left(s_{g}\right)\right)-F\left(P_{1}^{F}\left(s_{g}\right)\right)-G\left(\frac{P_{1}^{F}\left(s_{g}\right)}{w\left(s_{g}\right)}\right)\left(1-F\left(P_{1}^{F}\left(s_{g}\right)\right)\right. & =0 \\
F\left(\underline{\theta}^{F}\right)-F\left(P_{1}^{F}\left(s_{b}\right)\right)-G\left(\frac{P_{1}^{F}\left(s_{b}\right)}{w\left(s_{b}\right)}\right)\left(1-F\left(P_{1}^{F}\left(s_{b}\right)\right)\right. & =0
\end{aligned}
$$

Applying the implicit function theorem to equation (28) yields

$$
\begin{aligned}
\frac{d P_{1}^{F}\left(s_{g}\right)}{d \bar{m}} & =-\frac{f\left(\bar{m}-P_{1}^{F}\left(s_{g}\right)\right)}{-f\left(\bar{m}-P_{1}^{F}\left(s_{g}\right)\right)-f\left(P_{1}^{F}\left(s_{g}\right)\right)+f\left(P_{1}^{F}\left(s_{g}\right)\right) G\left(\frac{P_{1}^{F}\left(s_{g}\right)}{w\left(s_{g}\right)}\right)-\left(1-F\left(P_{1}^{F}\left(s_{g}\right)\right) g\left(\frac{P_{1}^{F}\left(s_{g}\right)}{w\left(s_{g}\right)}\right) \frac{1}{w\left(s_{g}\right)}\right.} \\
& =\frac{f\left(\bar{m}-P_{1}^{F}\left(s_{g}\right)\right)}{f\left(\bar{m}-P_{1}^{F}\left(s_{g}\right)\right)+f\left(P_{1}^{F}\left(s_{g}\right)\right)\left(1-G\left(\frac{P_{1}^{F}\left(s_{g}\right)}{w\left(s_{g}\right)}\right)\right)+\left(1-F\left(P_{1}^{F}\left(s_{g}\right)\right) g\left(\frac{P_{1}^{F}\left(s_{g}\right)}{w\left(s_{g}\right)}\right) \frac{1}{w\left(s_{g}\right)}\right.}
\end{aligned}
$$

Thus, $0<\frac{d P_{1}^{F}\left(s_{g}\right)}{d \bar{m}}<1$. As a result, $P_{1}^{F}\left(s_{g}\right)$ is increasing in $\bar{m}$. In addition, since $\underline{\theta}^{F}=\bar{m}-P_{1}^{F}\left(s_{g}\right)$, we have

$$
\frac{d \underline{\theta}^{F}}{d \bar{m}}=1-\frac{d P_{1}^{F}\left(s_{g}\right)}{d \bar{m}}>0
$$

which means that the homeownership rate $1-F\left(\underline{\theta}^{F}\right)$ is declining in $\bar{m}$.

Applying the implicit function theorem to equation (29) gives

$$
\frac{d P_{1}^{F}\left(s_{b}\right)}{d \underline{\theta}^{F}}=\frac{f\left(\underline{\theta}^{F}\right)}{f\left(P_{1}^{F}\left(s_{b}\right)\right)\left(1-G\left(\frac{P_{1}^{F}\left(s_{b}\right)}{w\left(s_{b}\right)}\right)\right)+\left(1-F\left(P_{1}^{F}\left(s_{b}\right)\right) g\left(\frac{P_{1}^{F}\left(s_{b}\right)}{w\left(s_{b}\right)}\right) \frac{1}{w\left(s_{b}\right)}\right.}>0 .
$$


Moreover,

$$
\frac{d P_{1}^{F}\left(s_{b}\right)}{d \bar{m}}=\frac{d P_{1}^{F}\left(s_{b}\right)}{d \underline{\theta}^{F}} \cdot \frac{d \underline{\theta}^{F}}{d \bar{m}}>0
$$

\section{Proof of Theorem 1}

According to (12), in the bad state the expected payment from the mortgage is:

$\hat{\Pi}\left(\bar{m}, w\left(s_{b}\right), P_{1}^{F}\left(s_{b}\right)\right)=\left(\frac{F\left(\hat{\theta}^{F}\right)-F\left(\underline{\theta}^{F}\right)}{1-F\left(\underline{\theta}^{F}\right)}\right) P_{1}^{F}\left(s_{b}\right)+\left(\frac{1-F\left(\hat{\theta}^{F}\right)}{1-F\left(\underline{\theta}^{F}\right)}\right)\left(G\left(\frac{\bar{m}}{w\left(s_{b}\right)}\right) P_{1}^{F}\left(s_{b}\right)+\left(1-G\left(\frac{\bar{m}}{w\left(s_{b}\right)}\right)\right) \bar{m}\right)$

where $\hat{\theta}^{F}=\bar{m}-P_{1}^{F}\left(s_{b}\right)$. The homeownership rate $\underline{\theta}^{F}$ is not affected by the loan modification in the bad state. We will investigate how $\hat{\Pi}\left(\bar{m}, w\left(s_{b}\right), P_{1}^{F}\left(s_{b}\right)\right)$ responds to a change in $\bar{m}$. Taking into account the fact that $\frac{d \hat{\theta}^{F}}{d \bar{m}}=1$, we can write

$$
\begin{aligned}
& \frac{d \hat{\Pi}\left(\bar{m}, w\left(s_{b}\right), P_{1}^{F}\left(s_{b}\right)\right)}{d \bar{m}}=\frac{f\left(\hat{\theta}^{F}\right)}{1-F\left(\underline{\theta}^{F}\right)} P_{1}^{F}\left(s_{b}\right)-\frac{f\left(\hat{\theta}^{F}\right)}{1-F\left(\underline{\theta}^{F}\right)}\left(G\left(\frac{\bar{m}}{w\left(s_{b}\right)}\right) P_{1}^{F}\left(s_{b}\right)+\left(1-G\left(\frac{\bar{m}}{w\left(s_{b}\right)}\right)\right) \bar{m}\right)+ \\
& +\left(\frac{1-F\left(\hat{\theta}^{F}\right)}{1-F\left(\underline{\theta}^{F}\right)}\right)\left(g\left(\frac{\bar{m}}{w\left(s_{b}\right)}\right) \frac{P_{1}^{F}\left(s_{b}\right)-\bar{m}}{w\left(s_{b}\right)}+\left(1-G\left(\frac{\bar{m}}{w\left(s_{b}\right)}\right)\right)\right) \\
& =\frac{1}{1-F\left(\underline{\theta}^{F}\right)}\left[\begin{array}{c}
-f\left(\hat{\theta}^{F}\right)\left(1-G\left(\frac{\bar{m}}{w\left(s_{b}\right)}\right)\right)\left(\bar{m}-P_{1}^{F}\left(s_{b}\right)\right)+ \\
\left(1-F\left(\hat{\theta}^{F}\right)\right)\left(g\left(\frac{\bar{m}}{w\left(s_{b}\right)}\right) \frac{P_{1}^{F}\left(s_{b}\right)-\bar{m}}{w\left(s_{b}\right)}+\left(1-G\left(\frac{\bar{m}}{w\left(s_{b}\right)}\right)\right)\right)
\end{array}\right] \\
& =\frac{1}{1-F\left(\underline{\theta}^{F}\right)}\left[\begin{array}{c}
-f\left(\hat{\theta}^{F}\right)\left(1-G\left(\frac{\bar{m}}{w\left(s_{b}\right)}\right)\right) \hat{\theta}^{F}+ \\
\left(1-F\left(\hat{\theta}^{F}\right)\right)\left(1-G\left(\frac{\bar{m}}{w\left(s_{b}\right)}\right)-g\left(\frac{\bar{m}}{w\left(s_{b}\right)}\right) \frac{\hat{\theta}^{F}}{w\left(s_{b}\right)}\right)
\end{array}\right] \\
& =\frac{1}{\left(1-F\left(\underline{\theta}^{F}\right)\right) w\left(s_{b}\right)}\left[w\left(s_{b}\right)\left(1-G\left(\frac{\bar{m}}{w\left(s_{b}\right)}\right)\right)\left(1-F\left(\hat{\theta}^{F}\right)-f\left(\hat{\theta}^{F}\right) \hat{\theta}^{F}\right)-\hat{\theta}^{F}\left(1-F\left(\hat{\theta}^{F}\right)\right) g\left(\frac{\bar{m}}{w\left(s_{b}\right)}\right)\right] \text {. }
\end{aligned}
$$

Thus $\frac{d \hat{\Pi}\left(\bar{m}, w\left(s_{b}\right), P_{1}^{F}\left(s_{b}\right)\right)}{d \bar{m}}>0$ if and only if

$$
w\left(s_{b}\right)\left(1-G\left(\frac{\bar{m}}{w\left(s_{b}\right)}\right)\right)\left(1-F\left(\hat{\theta}^{F}\right)-f\left(\hat{\theta}^{F}\right) \hat{\theta}^{F}\right)-\hat{\theta}^{F}\left(1-F\left(\hat{\theta}^{F}\right)\right) g\left(\frac{\bar{m}}{w\left(s_{b}\right)}\right)>0
$$

which can be rewritten as

$$
w\left(s_{b}\right) \frac{1-G\left(\frac{\bar{m}}{w\left(s_{b}\right)}\right)}{g\left(\frac{\bar{m}}{w\left(s_{b}\right)}\right)}>\frac{\hat{\theta}^{F}}{1-\frac{f\left(\hat{\theta}^{F}\right) \hat{\theta}^{F}}{1-F\left(\hat{\theta}^{F}\right)}}
$$

We note that when wages in the bad state $w\left(s_{b}\right)$ are high and mortgage payments $\bar{m}$ are low and Condition 1 is satisfied, the left hand side is high. At the same time, the right hand side is low, since 
$\hat{\theta}^{F}=\bar{m}-P_{1}^{F}\left(s_{b}\right)$ is bounded by $\bar{m}$. Thus, when $w\left(s_{b}\right)$ is high and $\bar{m}$ is low, $\frac{d \hat{\Pi}\left(\bar{m}, w\left(s_{b}\right), P_{1}^{F}\left(s_{b}\right)\right)}{d \bar{m}}>0$, which means that a reduction in $\bar{m}$ will reduce the lender's payoff.

When when $w\left(s_{b}\right)$ is low, $\bar{m}$ is high and Condition 1 is satisfied, the opposite is true, i.e., $\frac{d \hat{\Pi}\left(\bar{m}, w\left(s_{b}\right), P_{1}^{F}\left(s_{b}\right)\right)}{d \bar{m}}<0$, which means that a reduction in $\bar{m}$ will increase the lender's payoff.

\section{Proof of Theorem 2}

Adding (18a) to the above objective function (17) and simplifying allows us to rewrite this optimization problem as

$$
\max _{m(s)}\left(\begin{array}{c}
\bar{w} L+2 \theta-P_{0} \bar{R} \\
-\pi_{g}\left[\theta G\left(\frac{m\left(s_{g}\right)}{w\left(s_{g}\right)}\right)+G\left(\frac{P_{1}\left(s_{g}\right)}{w\left(s_{g}\right)}\right)\left(\theta-P_{1}\left(s_{g}\right)\right)\right] \\
-\pi_{b}\left[\theta G\left(\frac{m\left(s_{b}\right)}{w\left(s_{b}\right)}\right)+G\left(\frac{P_{1}\left(s_{b}\right)}{w\left(s_{b}\right)}\right)\left(\theta-P_{1}\left(s_{b}\right)\right)\right]
\end{array}\right)
$$

subject to $(18 \mathrm{a})$, where

$$
\bar{w} \equiv \pi_{b} w\left(s_{b}\right)+\pi_{g} w\left(s_{g}\right)
$$

Equation (30) follows from the fact that

$$
v(s, \theta)+\Pi(s, m(s))=w(s) L+2 \theta-\theta G\left(\frac{m(s)}{w(s)}\right)-G\left(\frac{P_{1}(s)}{w(s)}\right)\left(\theta-P_{1}(s)\right) .
$$

Deleting terms that do not depend on $m\left(s_{g}\right)$ or $m\left(s_{b}\right)$ from (30) simplifies the optimal contracting problem to

$$
\min _{m(s)} \pi_{g} G\left(\frac{m\left(s_{g}\right)}{w\left(s_{g}\right)}\right)+\pi_{b} G\left(\frac{m\left(s_{b}\right)}{w\left(s_{b}\right)}\right)
$$

subject to (18a). Thus, when the borrower does not default strategically, an optimal contract is the contract that minimizes the probability of liquidity default subject to the lender's break even condition.

The first order conditions with respect to $m\left(s_{g}\right)$ and $m\left(s_{b}\right)$ are given by:

$$
\begin{aligned}
& m\left(s_{g}\right): \frac{1}{w\left(s_{g}\right)} g\left(\frac{m\left(s_{g}\right)}{w\left(s_{g}\right)}\right)+\lambda\left(1-\frac{1}{w\left(s_{g}\right)} g\left(\frac{m\left(s_{g}\right)}{w\left(s_{g}\right)}\right)\left(m\left(s_{g}\right)-P_{1}\left(s_{g}\right)\right)-G\left(\frac{m\left(s_{g}\right)}{w\left(s_{g}\right)}\right)\right)=0 \\
& m\left(s_{b}\right): \frac{1}{w\left(s_{b}\right)} g\left(\frac{m\left(s_{b}\right)}{w\left(s_{b}\right)}\right)+\lambda\left(1-\frac{1}{w\left(s_{b}\right)} g\left(\frac{m\left(s_{b}\right)}{w\left(s_{b}\right)}\right)\left(m\left(s_{b}\right)-P_{1}\left(s_{b}\right)\right)-G\left(\frac{m\left(s_{b}\right)}{w\left(s_{b}\right)}\right)\right)=0,
\end{aligned}
$$

where $\lambda$ is the Lagrangian multiplier associated with constraint (18a). These conditions yield 
equation (20), since

$$
-\frac{1}{\lambda}=Q\left(s_{g}, m\left(s_{g}\right)\right)=Q\left(s_{b}, m\left(s_{b}\right)\right)
$$

where $Q(s, m(s))$ is given by $(19)$.

Equation (20) can be rewritten as

$$
w\left(s_{g}\right)\left(\frac{1-G\left(\frac{m\left(s_{g}\right)}{w\left(s_{g}\right)}\right)}{g\left(\frac{m\left(s_{g}\right)}{w\left(s_{g}\right)}\right)}-\frac{m\left(s_{g}\right)}{w\left(s_{g}\right)}\right)+P_{1}\left(s_{g}\right)=w\left(s_{b}\right)\left(\frac{1-G\left(\frac{m\left(s_{b}\right)}{w\left(s_{b}\right)}\right)}{g\left(\frac{m\left(s_{b}\right)}{w\left(s_{b}\right)}\right)}-\frac{m\left(s_{b}\right)}{w\left(s_{b}\right)}\right)+P_{1}\left(s_{b}\right) .
$$

Since $P_{1}\left(s_{g}\right)>P_{1}\left(s_{b}\right)$ and $w\left(s_{g}\right)>w\left(s_{b}\right)$, we have

$$
\frac{1-G\left(\frac{m\left(s_{g}\right)}{w\left(s_{g}\right)}\right)}{g\left(\frac{m\left(s_{g}\right)}{w\left(s_{g}\right)}\right)}-\frac{m\left(s_{g}\right)}{w\left(s_{g}\right)}<\frac{1-G\left(\frac{m\left(s_{b}\right)}{w\left(s_{b}\right)}\right)}{g\left(\frac{m\left(s_{b}\right)}{w\left(s_{b}\right)}\right)}-\frac{m\left(s_{b}\right)}{w\left(s_{b}\right)}
$$

If $G$ satisfies Condition 1, then $\frac{1-G(x)}{g(x)}-x$ is decreasing in $x$. Hence, equation (31) implies that

$$
\frac{m\left(s_{g}\right)}{w\left(s_{g}\right)}>\frac{m\left(s_{b}\right)}{w\left(s_{b}\right)}
$$

meaning the default rate is going to be higher in the good state:

$$
G\left(\frac{m\left(s_{g}\right)}{w\left(s_{g}\right)}\right)>G\left(\frac{m\left(s_{b}\right)}{w\left(s_{b}\right)}\right)
$$

In the uniform example, $Q(s, m(s))$ becomes

$$
Q(s, m(s))=w(s)+P_{1}(s)-2 m(s)
$$

which yields (21).

Finally, Section 5.1 shows that the borrower will not default strategically if and only if $\theta \geq$ $\max _{s}\left[\tilde{m}(s)-P_{1}(s)\right]$.

\section{Proof of Theorem 3}

Consider a contract $m^{\prime}$ such that $m^{\prime}\left(s_{g}\right)-m^{\prime}\left(s_{b}\right) \neq P_{1}^{\prime}\left(s_{g}\right)-P_{1}^{\prime}\left(s_{b}\right)$, where $P_{1}^{\prime}(s)$ are home prices at time $t=1$. We will show that this contract cannot be an equilibrium contract. 
Let's assume, for the sake of the argument, that

$$
\underline{\theta}^{\prime} \equiv m^{\prime}\left(s_{g}\right)-P_{1}^{\prime}\left(s_{g}\right)<m^{\prime}\left(s_{b}\right)-P_{1}^{\prime}\left(s_{b}\right) \equiv \hat{\theta}^{\prime}
$$

Then, borrowers with $\theta \in\left(\underline{\theta}^{\prime}, \hat{\theta}^{\prime}\right)$ will buy homes at time $t=0$, and default strategically in the bad state at time $t=0+$. A borrowers with $\theta \geq \hat{\theta}^{\prime}$ will not default strategically, and will enjoy expected utility

$$
\pi_{g} v\left(s_{g}, \theta\right)+\pi_{b} v\left(s_{b}, \theta\right)
$$

where

$$
v(s, \theta)=w(s) L+\left[1-G\left(\frac{m^{\prime}(s)}{w(s)}\right)\right]\left(2 \theta-m^{\prime}(s)\right)+\left[G\left(\frac{m^{\prime}(s)}{w(s)}\right)-G\left(\frac{P_{1}^{\prime}(s)}{w(s)}\right)\right]\left(\theta-P_{1}^{\prime}(s)\right) .
$$

is the borrower's expected utility in state $s$ according to (16). Taking the derivative of $v$ with respect to $m^{\prime}(s)$ yields

$$
\frac{\partial v(s, \theta)}{\partial m^{\prime}(s)}=-\left[1-G\left(\frac{m^{\prime}(s)}{w(s)}\right)\right]-\frac{g\left(\frac{m^{\prime}(s)}{w(s)}\right)}{w(s)}\left(\theta-\left(m^{\prime}(s)-P_{1}^{\prime}(s)\right)\right) .
$$

Now, let's consider mortgage $m^{\prime \prime}$ such that

$$
\begin{aligned}
& m^{\prime \prime}\left(s_{g}\right)=m^{\prime}\left(s_{g}\right)+\varepsilon_{g}, \\
& m^{\prime \prime}\left(s_{b}\right)=m^{\prime}\left(s_{b}\right)+\varepsilon_{b},
\end{aligned}
$$

where $\varepsilon_{g}>0$ and $\varepsilon_{b}<0$ are small. A borrowers with $\theta \geq \hat{\theta}^{\prime}$ prefers contract $m^{\prime \prime}$ over $m^{\prime}$ if

$$
\pi_{g} \frac{\partial v\left(s_{g}, \theta\right)}{\partial m^{\prime}\left(s_{g}\right)} \varepsilon_{g}+\pi_{b} \frac{\partial v\left(s_{b}, \theta\right)}{\partial m^{\prime}\left(s_{b}\right)} \varepsilon_{b} \geq 0
$$

Plugging (32) into (33) yields

$$
\varepsilon_{b} \leq-\frac{\pi_{g}\left[1-G\left(\frac{m^{\prime}\left(s_{g}\right)}{w\left(s_{g}\right)}\right)+\frac{g\left(\frac{m^{\prime}\left(s_{g}\right)}{w\left(s_{g}\right)}\right)}{w\left(s_{g}\right)}\left(\theta-\underline{\theta}^{\prime}\right)\right]}{\pi_{b}\left[1-G\left(\frac{m^{\prime}\left(s_{b}\right)}{w\left(s_{b}\right)}\right)+\frac{g\left(\frac{m^{\prime}\left(s_{b}\right)}{w\left(s_{b}\right)}\right)}{w\left(s_{b}\right)}\left(\theta-\hat{\theta}^{\prime}\right)\right]} \varepsilon_{g} .
$$


Let

$$
\varepsilon_{b}=-\max _{\theta \in\left[\hat{\theta}^{\prime}, \bar{\theta}\right]} \frac{\pi_{g}\left[1-G\left(\frac{m^{\prime}\left(s_{g}\right)}{w\left(s_{g}\right)}\right)+\frac{g\left(\frac{m^{\prime}\left(s_{g}\right)}{w\left(s_{g}\right)}\right)}{w\left(s_{g}\right)}\left(\theta-\underline{\theta}^{\prime}\right)\right]}{\pi_{b}\left[1-G\left(\frac{m^{\prime}\left(s_{b}\right)}{w\left(s_{b}\right)}\right)+\frac{g\left(\frac{m^{\prime}\left(s_{b}\right)}{w\left(s_{b}\right)}\right)}{w\left(s_{b}\right)}\left(\theta-\hat{\theta}^{\prime}\right)\right]} \varepsilon_{g} .
$$

Then, all borrowers who do not default strategically, i.e., with $\theta \in\left[\hat{\theta}^{\prime}, \bar{\theta}\right]$, prefer contract $m^{\prime \prime}$ over $m^{\prime}$. However, borrowers who default strategically in the bad state, i.e., with $\theta \in\left(\underline{\theta}^{\prime}, \hat{\theta}^{\prime}\right)$, prefer contract $m^{\prime}$ over $m^{\prime \prime}$, since they do not pay mortgage in the bad state and contract $m^{\prime}$ has lower payment in the good state.

If $m^{\prime}$ is an equilibrium mortgage contract, then lenders must make zero profit:

$$
\pi_{g} \Pi\left(s_{g}, m^{\prime}\left(s_{g}\right)\right)+\pi_{b} \hat{\Pi}\left(s_{b}, m^{\prime}\left(s_{b}\right)\right)-P_{0} \bar{R}=0,
$$

where

$$
\begin{aligned}
& \Pi\left(s_{g}, m^{\prime}\left(s_{g}\right)\right)=\left(1-G\left(\frac{m^{\prime}\left(s_{g}\right)}{w\left(s_{g}\right)}\right)\right) m^{\prime}\left(s_{g}\right)+G\left(\frac{m^{\prime}\left(s_{g}\right)}{w\left(s_{g}\right)}\right) P_{1}^{\prime}\left(s_{g}\right), \\
& \hat{\Pi}\left(s_{b}, m^{\prime}\left(s_{b}\right)\right)=\Pi\left(s_{b}, m^{\prime}\left(s_{b}\right)\right)-\frac{\left(F\left(\hat{\theta}^{\prime}\right)-F\left(\underline{\theta}^{\prime}\right)\right)}{\left(1-F\left(\underline{\theta}^{\prime}\right)\right)}\left(1-G\left(\frac{m^{\prime}\left(s_{b}\right)}{w\left(s_{b}\right)}\right)\right)\left(m^{\prime}\left(s_{b}\right)-P_{1}^{\prime}\left(s_{b}\right)\right)
\end{aligned}
$$

are the lender's expected payoffs in the good and the bad states according to (11) and (13).

$$
\frac{\partial \Pi\left(s, m^{\prime}(s)\right)}{\partial m^{\prime}(s)}=\left(1-G\left(\frac{m^{\prime}(s)}{w(s)}\right)\right)-\frac{g\left(\frac{m^{\prime}(s)}{w(s)}\right)}{w(s)}\left(m^{\prime}(s)-P_{1}^{\prime}(s)\right) .
$$

Since there are no strategic defaults under contract $m^{\prime \prime}$, the lender's payoff under contract $m^{\prime \prime}$ is

$$
\begin{aligned}
& \pi_{g} \Pi\left(s_{g}, m^{\prime \prime}\left(s_{g}\right)\right)+\pi_{b} \Pi\left(s_{b}, m^{\prime \prime}\left(s_{b}\right)\right)-P_{0} \bar{R} \\
= & \pi_{g}\left(\Pi\left(s_{g}, m^{\prime}\left(s_{g}\right)\right)+\frac{\partial \Pi\left(s_{g}, m^{\prime}\left(s_{g}\right)\right)}{\partial m^{\prime}\left(s_{g}\right)} \varepsilon_{g}\right)+\pi_{b}\left(\Pi\left(s_{b}, m^{\prime}\left(s_{b}\right)\right)+\frac{\partial \Pi\left(s_{b}, m^{\prime}\left(s_{b}\right)\right)}{\partial m^{\prime}\left(s_{b}\right)} \varepsilon_{b}\right)-P_{0} \bar{R} \\
= & \pi_{b} \frac{\left(F\left(\hat{\theta}^{\prime}\right)-F\left(\underline{\theta}^{\prime}\right)\right)}{\left(1-F\left(\underline{\theta}^{\prime}\right)\right)}\left(1-G\left(\frac{m^{\prime}\left(s_{b}\right)}{w\left(s_{b}\right)}\right)\right)\left(m^{\prime}\left(s_{b}\right)-P_{1}^{\prime}\left(s_{b}\right)\right)+\pi_{g} \frac{\partial \Pi\left(s_{g}, m^{\prime}\left(s_{g}\right)\right)}{\partial m^{\prime}\left(s_{g}\right)} \varepsilon_{g}+\pi_{b} \frac{\partial \Pi\left(s_{b}, m^{\prime}\left(s_{b}\right)\right)}{\partial m^{\prime}\left(s_{b}\right)} \varepsilon_{b},
\end{aligned}
$$

where equation (36) follows from (34) and (35). The first term in (36) is strictly positive since $m^{\prime}\left(s_{b}\right)-P_{1}^{\prime}\left(s_{b}\right)=\hat{\theta}^{\prime}$, and the last two terms can be made arbitrarily small compared to the first term, since they are proportional to $\varepsilon_{g}$ and $\varepsilon_{b}$. Thus, the lender makes a strictly positive profit 
with contract $m^{\prime \prime}$. As a result, mortgage $m^{\prime}$ cannot be an equilibrium contract.

If borrowers default strategically in the good state under contract $m^{\prime \prime}$, i.e.,

$$
m^{\prime}\left(s_{g}\right)-P_{1}^{\prime}\left(s_{g}\right)>m^{\prime}\left(s_{b}\right)-P_{1}^{\prime}\left(s_{b}\right),
$$

then we can use the above argument to show that a lender can make a positive profit under $m^{\prime \prime}$, if he slightly increases the mortgage payment in the bad state $\left(\varepsilon_{g}<0\right.$ and $\left.\varepsilon_{b}>0\right)$. Thus, an equilibrium contract $m^{*}$ must satisfy

$$
m^{*}\left(s_{g}\right)-m^{*}\left(s_{b}\right)=P_{1}^{*}\left(s_{g}\right)-P_{1}^{*}\left(s_{b}\right) .
$$

\section{Proof of Lemma 1}

A borrowers with $\theta \geq \hat{\theta}$ does not default strategically, and his payoffs in state $s$ under contracts $m^{*}$ and $m$ are given by

$$
\begin{aligned}
v\left(s, \theta, m^{*}(s)\right) & =w(s) L+\left(1-G\left(\frac{m^{*}(s)}{w(s)}\right)\right)\left(2 \theta-m^{*}(s)\right)+\left(G\left(\frac{m^{*}(s)}{w(s)}\right)-G\left(\frac{P_{1}(s)}{w(s)}\right)\right)\left(\theta-P_{1}^{*}(s)\right) \\
& =w(s) L+\left(1-G\left(\frac{P_{1}(s)}{w(s)}\right)\right)\left(\theta-P_{1}^{*}(s)\right)+\left(1-G\left(\frac{m^{*}(s)}{w(s)}\right)\right)\left(\theta-\left(m^{*}(s)-P_{1}^{*}(s)\right)\right)(37) \\
v(s, \theta, m(s)) & =w(s) L+\left(1-G\left(\frac{m(s)}{w(s)}\right)\right)(2 \theta-m(s))+\left(G\left(\frac{m(s)}{w(s)}\right)-G\left(\frac{P_{1}(s)}{w(s)}\right)\right)\left(\theta-P_{1}^{*}(s)\right) \\
& =w(s) L+\left(1-G\left(\frac{P_{1}(s)}{w(s)}\right)\right)\left(\theta-P_{1}^{*}(s)\right)+\left(1-G\left(\frac{m(s)}{w(s)}\right)\right)\left(\theta-\left(m(s)-P_{1}^{*}(s)\right)\right) .(38)
\end{aligned}
$$

We note that the first two terms in (37) and (38) do not depend on mortgage payments.

The borrower prefers mortgage $m$ over $m^{*}$, if

$$
\pi_{g} v\left(s_{g}, \theta, m\left(s_{g}\right)\right)+\pi_{b} v\left(s_{b}, \theta, m\left(s_{b}\right)\right) \geq \pi_{g} v\left(s_{g}, \theta, m^{*}\left(s_{g}\right)\right)+\pi_{b} v\left(s_{b}, \theta, m^{*}\left(s_{b}\right)\right) .
$$

Both sides of the inequality can be further simplified as follows.

$$
\begin{aligned}
& \pi_{g}\left(1-G\left(\frac{m^{*}\left(s_{g}\right)}{w\left(s_{g}\right)}\right)\right)\left(\theta-\left(m^{*}\left(s_{g}\right)-P_{1}^{*}\left(s_{g}\right)\right)\right)+\pi_{b}\left(1-G\left(\frac{m^{*}\left(s_{b}\right)}{w\left(s_{b}\right)}\right)\right)\left(\theta-\left(m^{*}\left(s_{b}\right)-P_{1}^{*}\left(s_{b}\right)\right)\right) \\
= & \pi_{g}\left(1-G\left(\frac{m^{*}\left(s_{g}\right)}{w\left(s_{g}\right)}\right)\right)\left(\theta-\theta^{*}\right)+\pi_{b}\left(1-G\left(\frac{m^{*}\left(s_{b}\right)}{w\left(s_{b}\right)}\right)\right)\left(\theta-\theta^{*}\right) \\
= & z^{*}\left(\theta-\theta^{*}\right) .
\end{aligned}
$$


Similarly,

$$
\begin{aligned}
& \pi_{g}\left(1-G\left(\frac{m\left(s_{g}\right)}{w\left(s_{g}\right)}\right)\right)\left(\theta-\left(m\left(s_{g}\right)-P_{1}^{*}\left(s_{g}\right)\right)\right)+\pi_{b}\left(1-G\left(\frac{m\left(s_{b}\right)}{w\left(s_{b}\right)}\right)\right)\left(\theta-\left(m\left(s_{b}\right)-P_{1}^{*}\left(s_{b}\right)\right)\right) \\
= & z(\theta-\underline{\theta})-\pi_{\hat{s}}\left(1-G\left(\frac{m(\hat{s})}{w(\hat{s})}\right)\right)(\hat{\theta}-\underline{\theta}) .
\end{aligned}
$$

Thus, the borrower prefers mortgage $m$ over $m^{*}$, if

$$
z(\theta-\underline{\theta})-\pi_{\hat{s}}\left(1-G\left(\frac{m(\hat{s})}{w(\hat{s})}\right)\right)(\hat{\theta}-\underline{\theta}) \geq z^{*}\left(\theta-\theta^{*}\right),
$$

or

$$
\theta \geq \frac{\underline{\theta} z-\theta^{*} z^{*}+\pi_{\hat{s}}\left(1-G\left(\frac{m(\hat{s})}{w(\hat{s})}\right)\right)(\hat{\theta}-\underline{\theta})}{z-z^{*}}
$$

which yields (26).

A borrower with $\theta<\hat{\theta}$ defaults strategically in state $\hat{s}$, and his payoff in this state is given by

$$
\hat{v}(\hat{s}, \theta, m(\hat{s}))=w(\hat{s}) L+\left(1-G\left(\frac{P_{1}(\hat{s})}{w(\hat{s})}\right)\right)\left(\theta-P_{1}^{*}(\hat{s})\right) .
$$

The borrower prefers mortgage $m$ over $m^{*}$, if

$$
\begin{aligned}
\pi_{\hat{s}} \hat{v}(\hat{s}, \theta, m(\hat{s}))+\pi_{\hat{s}^{-}} v\left(s_{\hat{s}^{-}}, \theta, m\left(s_{\hat{s}^{-}}\right)\right) & \geq \pi_{g} v\left(s_{g}, \theta, m^{*}\left(s_{g}\right)\right)+\pi_{b} v\left(s_{b}, \theta, m^{*}\left(s_{b}\right)\right), \\
\pi_{\hat{s}^{-}}\left(1-G\left(\frac{m\left(\hat{s}^{-}\right)}{w\left(\hat{s}^{-}\right)}\right)\right)\left(\theta-\left(m\left(\hat{s}^{-}\right)-P_{1}^{*}\left(\hat{s}^{-}\right)\right)\right) & \geq z^{*}\left(\theta-\theta^{*}\right), \\
\theta & \leq \frac{z^{*} \theta^{*}-\pi_{\hat{s}^{-}}\left(1-G\left(\frac{m\left(\hat{s}^{-}\right)}{w\left(\hat{s}^{-}\right)}\right)\right) \underline{\theta}}{z^{*}-\pi_{\hat{s}^{-}}\left(1-G\left(\frac{m\left(\hat{s}^{-}\right)}{w\left(\hat{s}^{-}\right)}\right)\right)},
\end{aligned}
$$

which yields (25).

\section{Proof of Theorem 4}

The lender's payoff in state $\hat{s}^{-}$under mortgage $m$ is equal to

$$
\begin{aligned}
\Pi\left(\hat{s}^{-}, m\left(\hat{s}^{-}\right)\right) & =\left(1-G\left(\frac{m\left(\hat{s}^{-}\right)}{w\left(\hat{s}^{-}\right)}\right)\right) m\left(\hat{s}^{-}\right)+G\left(\frac{m\left(\hat{s}^{-}\right)}{w\left(\hat{s}^{-}\right)}\right) P_{1}^{*}\left(\hat{s}^{-}\right) \\
& =\left(1-G\left(\frac{m\left(\hat{s}^{-}\right)}{w\left(\hat{s}^{-}\right)}\right)\right)\left(m\left(\hat{s}^{-}\right)-P_{1}^{*}\left(\hat{s}^{-}\right)\right)+P_{1}^{*}\left(\hat{s}^{-}\right) \\
& =\left(1-G\left(\frac{m\left(\hat{s}^{-}\right)}{w\left(\hat{s}^{-}\right)}\right)\right) \underline{\theta}+P_{1}^{*}\left(\hat{s}^{-}\right) .
\end{aligned}
$$


The payoff in state $\hat{s}$ is given by

$$
\begin{aligned}
\hat{\Pi}(\hat{s}, m(\hat{s})) & =\left(1-\xi\left(m\left(s_{g}\right), m\left(s_{b}\right)\right)\right)\left(\left(1-G\left(\frac{m(\hat{s})}{w(\hat{s})}\right)\right) m(\hat{s})+G\left(\frac{m(\hat{s})}{w(\hat{s})}\right) P_{1}^{*}(\hat{s})\right)+\xi\left(m\left(s_{g}\right), m\left(s_{b}\right)\right) P_{1}^{*}(\hat{s}) \\
& =\left(1-G\left(\frac{m(\hat{s})}{w(\hat{s})}\right)\right)\left(1-\xi\left(m\left(s_{g}\right), m\left(s_{b}\right)\right)\right)\left(m(\hat{s})-P_{1}^{*}(\hat{s})\right)+P_{1}^{*}(\hat{s}) \\
& =\left(1-G\left(\frac{m(\hat{s})}{w(\hat{s})}\right)\right)\left(1-\xi\left(m\left(s_{g}\right), m\left(s_{b}\right)\right)\right) \hat{\theta}+P_{1}^{*}(\hat{s})
\end{aligned}
$$

The expected payoff under mortgage $m$ is

$$
\begin{aligned}
& \pi_{\hat{s}^{-}} \Pi\left(\hat{s}^{-}, m\left(\hat{s}^{-}\right)\right)+\pi_{\hat{s}}\left(1-G\left(\frac{m(\hat{s})}{w(\hat{s})}\right)\right) \hat{\Pi}(\hat{s}, m(\hat{s})) \\
= & \pi_{\hat{s}^{-}}\left(1-G\left(\frac{m\left(\hat{s}^{-}\right)}{w\left(\hat{s}^{-}\right)}\right)\right) \underline{\theta}+\pi_{\hat{s}}\left(1-G\left(\frac{m(\hat{s})}{w(\hat{s})}\right)\right)\left(1-\xi\left(m\left(s_{g}\right), m\left(s_{b}\right)\right)\right) \hat{\theta}+\pi_{\hat{s}^{-}} P_{1}^{*}\left(\hat{s}^{-}\right)+\pi_{\hat{s}} P_{1}^{*}(\hat{s}) .
\end{aligned}
$$

In an equilibrium, this payoff must be maximized by a HEIM mortgage. Since the last two terms do not depend on the mortgage payments, an equilibrium HEIM contract must solve the problem given by equation $(27)$.

\section{Proof of Proposition 7}

Equations (9), (10) and (24) that determine equilibrium prices $P_{1}^{F}\left(s_{g}\right), P_{1}^{F}\left(s_{b}\right), P_{1}^{*}\left(s_{g}\right)$ and $P_{1}^{*}\left(s_{b}\right)$ can be rewritten as

$$
\begin{aligned}
F\left(\bar{m}-P_{1}^{F}\left(s_{g}\right)\right)-F\left(P_{1}^{F}\left(s_{g}\right)\right)-G\left(\frac{P_{1}^{F}\left(s_{g}\right)}{w\left(s_{g}\right)}\right)\left(1-F\left(P_{1}^{F}\left(s_{g}\right)\right)\right. & =0 \\
F\left(\underline{\theta}^{F}\right)-F\left(P_{1}^{F}\left(s_{b}\right)\right)-G\left(\frac{P_{1}^{F}\left(s_{b}\right)}{w\left(s_{b}\right)}\right)\left(1-F\left(P_{1}^{F}\left(s_{b}\right)\right)\right. & =0 \\
F\left(m^{*}\left(s_{g}\right)-P_{1}^{*}\left(s_{g}\right)\right)-F\left(P_{1}^{*}\left(s_{g}\right)\right)-G\left(\frac{P_{1}^{*}\left(s_{g}\right)}{w\left(s_{g}\right)}\right)\left(1-F\left(P_{1}^{*}\left(s_{g}\right)\right)\right. & =0 \\
F\left(\theta^{*}\right)-F\left(P_{1}^{*}\left(s_{b}\right)\right)-G\left(\frac{P_{1}^{*}\left(s_{b}\right)}{w\left(s_{b}\right)}\right)\left(1-F\left(P_{1}^{*}\left(s_{b}\right)\right)\right. & =0
\end{aligned}
$$

Applying the implicit function theorem to equation (39), we can write

$$
\begin{aligned}
\frac{d P_{1}^{F}\left(s_{g}\right)}{d \bar{m}} & =-\frac{f\left(\bar{m}-P_{1}^{F}\left(s_{g}\right)\right)}{-f\left(\bar{m}-P_{1}^{F}\left(s_{g}\right)\right)-f\left(P_{1}^{F}\left(s_{g}\right)\right)+f\left(P_{1}^{F}\left(s_{g}\right)\right) G\left(\frac{P_{1}^{F}\left(s_{g}\right)}{w\left(s_{g}\right)}\right)-\left(1-F\left(P_{1}^{F}\left(s_{g}\right)\right) g\left(\frac{P_{1}^{F}\left(s_{g}\right)}{w\left(s_{g}\right)}\right) \frac{1}{w\left(s_{g}\right)}\right.} \\
& =\frac{f\left(\bar{m}-P_{1}^{F}\left(s_{g}\right)\right)}{f\left(\bar{m}-P_{1}^{F}\left(s_{g}\right)\right)+f\left(P_{1}^{F}\left(s_{g}\right)\right)\left(1-G\left(\frac{P_{1}^{F}\left(s_{g}\right)}{w\left(s_{g}\right)}\right)\right)+\left(1-F\left(P_{1}^{F}\left(s_{g}\right)\right) g\left(\frac{P_{1}^{F}\left(s_{g}\right)}{w\left(s_{g}\right)}\right) \frac{1}{w\left(s_{g}\right)}\right.}
\end{aligned}
$$

We note that $0<\frac{d P_{1}^{F}\left(s_{g}\right)}{d \bar{m}}<1$. 
Equations (39) and (41) are identical, except for $\bar{m}$ and $m^{*}\left(s_{g}\right)$. Since $\frac{d P_{1}^{F}\left(s_{g}\right)}{d \bar{m}}>0$, then $P_{1}^{*}\left(s_{g}\right)>P_{1}^{F}\left(s_{g}\right)$ if and only if $m^{*}\left(s_{g}\right)>\bar{m}$.

Since $\frac{d P_{1}^{F}\left(s_{g}\right)}{d \bar{m}}<1$, then $\theta^{*}>\underline{\theta}^{F}$ if and only if $m^{*}\left(s_{g}\right)>\bar{m}$

Finally, applying the implicit function theorem to equation (40) gives

$$
\frac{d P_{1}^{F}\left(s_{b}\right)}{d \underline{\theta}^{F}}=\frac{f\left(\underline{\theta}^{F}\right)}{f\left(P_{1}^{F}\left(s_{b}\right)\right)\left(1-G\left(\frac{P_{1}^{F}\left(s_{b}\right)}{w\left(s_{b}\right)}\right)\right)+\left(1-F\left(P_{1}^{F}\left(s_{b}\right)\right) g\left(\frac{P_{1}^{F}\left(s_{b}\right)}{w\left(s_{b}\right)}\right) \frac{1}{w\left(s_{b}\right)}\right.}>0
$$

Since equations (40) and (42) are identical, except for $\underline{\theta}^{F}$ and $\theta^{*}$, the fact that $\frac{d P_{1}^{F}\left(s_{b}\right)}{d \underline{\theta}^{F}}>0$ implies that $P_{1}^{*}\left(s_{b}\right)>P_{1}^{F}\left(s_{b}\right)$ if and only if $m^{*}\left(s_{g}\right)>\bar{m}$.

\section{Proof of Theorem 5}

Let $\bar{m}$ be the equilibrium FRM. Consider the following modification of the FRM mortgage: $\ddot{m}\left(s_{g}\right)=$ $\bar{m}$, and $\ddot{m}\left(s_{b}\right)=\bar{m}-\left(P_{1}^{F}\left(s_{g}\right)-P_{1}^{F}\left(s_{b}\right)\right)$, where $P_{1}^{F}\left(s_{g}\right)$ and $P_{1}^{F}\left(s_{b}\right)$ are the home prices in the FRM equilibrium. This modification does not change the lender's payoff in the good state. According to Theorem 1, if wages in the bad state $w\left(s_{g}\right)$ are high compared to the FRM payments $\bar{m}$, then this modification will reduce the lender's payoff in the bad state. On the other hand, if $w\left(s_{g}\right)$ is low compared $\bar{m}$, then this modification will increase the lender's payoff in the bad state.

Consider the special case, in which the FRM modification does not change the lender's payoff in the bad state. In this case, $P_{1}^{F}\left(s_{g}\right)$ and $P_{1}^{F}\left(s_{b}\right)$ are also the home prices in the HEIM equilibrium, and $\ddot{m}\left(s_{g}\right)$ and $\ddot{m}\left(s_{b}\right)$ is the equilibrium HEIM contract. Indeed, according to Proposition 7, when $\ddot{m}\left(s_{g}\right)=\bar{m}$, home prices at time $t=1$ are the same in the FRM and HEIM equilibria, and the lender breaks even under the HEIM contract.

In the case when $w\left(s_{g}\right)$ is sufficiently low compared to $\bar{m}$, the modification leads to a higher expected payoff for the lender. Thus, an equilibrium HEIM contract will charge less than $\bar{m}$ in both states. According to Proposition 7, the HEIM equilibrium will have lower home prices in both states and higher homeownership than those in the equilibrium with FRMs. In this case, the HEIM equilibrium Pareto dominates the FRM equilibrium, since all homeowner are strictly better off with the HEIM contract and there are more of them at $t=0$ and $t=1$. In addition, foreclosure costs are lower in the HEIM equilibrium.

In the case when $w\left(s_{g}\right)$ is sufficiently high compared to $\bar{m}$, the modification leads to a lower expected payoff for the lender. Thus, the equilibrium HEIM contract must charge more than $\bar{m}$ in 
the good state to break even. As a result, according to Proposition 7, the HEIM equilibrium will have higher home prices in both states and lower homeownership compared to the FRM equilibrium. Consequently, workers with $\theta \in\left(\underline{\theta}^{F}, \theta^{*}\right]$ are better off in the FRM equilibrium, where they buy homes at time $t=0$ and enjoy homeownership utility in the first period in the good state. In the HEIM equilibrium, these workers enjoy no homeownership utility in the first period, and have to pay higher prices at time $t=1$ to enjoy it in the second period. 


\section{References}

Agarwal, S., G. Amromin, I. Ben-David, S. Chomsisengphet, T. Piskorski, and A. Seru, 2012, Policy Intervention in Debt Renegotiation: Evidence from Home Affordable Modification Program, forthcoming in the Journal of Political Economy.

Agarwal, S., G. Amromin, S. Chomsisengphet, T. Landvoigt, T. Piskorski, A. Seru, and V. Yao. 2015, Mortgage Refinancing, Consumer Spending, and Competition: Evidence from the Home Affordable Refinancing Program, Working Paper.

Biais, B., T. Mariotti, G. Plantin, and J.-Ch. Rochet, 2007, Dynamic Security Design: Convergence to Continuous Time and Asset Pricing Implications, Review of Economic Studies 74, $345-90$.

Bolton, P., and D. S. Scharfstein, 1990, A Theory of Predation Based on Agency Problems in Financial Contracting, American Economic Review 80, 93-106.

Bolton, P., T. Santos, and J. Scheinkman, 2016, Savings Gluts and Financial Fragility, Working Paper.

Brunnermeier, M. K., and Y. Sannikov, 2014, A Macroeconomic Model with a Financial Sector, American Economic Review 104, 379-421.

Campbell, J. Y., 2013, Mortgage Market Design, Review of Finance 17, 1-33.

Campbell, J. Y., and J. F. Cocco, 2003. Household Risk Management and Optimal Mortgage Choice. Quarterly Journal of Economics 118: 1449-1494.

Campbell J. Y., and J. F.Cocco, 2015, A Model of Mortgage Default, Journal of Finance 70, $1495-1554$.

Caplin, A., Cunningham, N., Engler, M., and Pollack, F. 2008, Facilitating Shared Appreciation Mortgages to Prevent Crashes and Affordability Crises, Hamilton Project Discussion Paper, Brookings Institute.

Chari, V. V., and R. Jagannathan, 1989, Adverse Selection in a Model of Real Estate Lending, Journal of Finance 44, 499-508. 
DeMarzo, P. M., and Y. Sannikov, 2006, Optimal Security Design and Dynamic Capital Structure in a Continuous-Time Agency Model, Journal of Finance 61, 2681-2724.

DeMarzo, P. M., and M. J. Fishman, 2007, Optimal Long-Term Financial Contracting, Review of Financial Studies 20, 2079-2128.

Diamond, Douglas W., 1984, Financial Intermediation and Delegated Monitoring, Review of Economic Studies 51, 393-414.

Di Maggio, M., A. Kermani, and R. Ramcharan, 2014, Monetary Policy Pass-Through: Household Consumption and Voluntary Deleveraging, Working Paper.

Di Maggio, M., A. Kermani, B. Keys, T. Piskorski, R. Ramcharan, A. Seru, V. Yao, 2017, Interest Rate Pass-Through: Mortgage Rates, Household Consumption and Voluntary Deleveraging, Working Paper.

Dunn, K. B., and C. S. Spatt, 1985, Prepayment Penalties and the Due-On-Sale Clause, Journal of Finance 40, 293-308.

Dunn, K. B., C. S. Spatt, 1988. Private Information and Incentives: Implications for Mortgage Contract Terms and Pricing. Journal of Real Estate Finance and Economics 1, 47-60.

Dubey, P., J. Geanakoplos, and M. Shubik, 2005, Default and Punishment in General Equilibrium, Econometrica 73, 1-37.

Eberly, J., and A. Krishnamurthy, 2014, Efficient Credit Polices in a Housing Crisis, Fall 2014 Brookings Panel on Economic Activity.

Farhi, E., M. Golosov, and A. Tsyvinski, 2009, A Theory of Liquidity and Regulation of Financial Intermediation, Review of Economic Studies 76, 973-992.

Favilukis, J., S. Ludvingson, and S. Van Nieuwerburgh, 2016, The Macroeconomic Effects of Housing Wealth, Housing Finance, and Limited Risk Sharing in General Equilibrium, forthcoming in the Journal of Politcal Economy.

Garmaise, M., 2015, Borrower Misreporting and Loan Performance, Journal of Finance 70, 449484 . 
Green, R. K. and S. M. Wachter, 2005, The American Mortgage in Historical and International Context, Journal of Economic Perspectives 19, 93-114.

Greenwald, D. L., T. Landvoigt, and S. Van Nieuwerburgh, 2017, Financial Fragility with Sam?, Working Paper.

Griffin, J. M., and G. Maturana, 2016, Who Facilitated Misreporting in Securitized Loans?, Review of Financial Studies 29, 384-419.

Guren, A., A. Krishnamurty, T. McQuade, 2017, Mortgage Design in an Equilibrium Model of the Housing Market, Working Paper.

Hartman-Glaser, B., and B. Hebert, 2016, The Insurance is the Lemon: Falling to Index Contracts, Working Paper.

He, Z., and K. Milbradt, 2014, Endogenous Liquidity and Defaultable Bonds, Econometrica 82, $1443-1508$.

Jiang, W., A. A. Nelson, and E. Vytlacil, 2014, Liar's Loan? Effects of Origination Channel on Mortgage Delinquency, Review of Economics and Statistics 96, 1-18.

Kaplan, G., K. Mitman, and G. Violante, 2016, Consumption and House Prices in the Great Recession: Model Meets Evidence, Working Paper.

Keys, B. J., T. Mukherjee, A. Seru, and V. Vig, 2010, Did Securitization Lead to Lax Screening? Evidence from Subprime Loans, Quarterly Journal of Economics 125, 307-362.

Keys, B. J., T. Piskorski, A. Seru, and V. Vig, 2013, "Mortgage Financing in the Housing Boom and Bust." In Housing and Financial Crisis, edited by Edward L. Glaeser and Todd Sinai, 143-204. Chicago: University of Chicago Press

Keys, B. J., T. Piskorski, A. Seru, and V. Yao, 2014, Mortgage Rates, Household Balance Sheets, and Real Economy, NBER Working Paper No. 20561.

Kiyotaki N., and J. Moore, 1997, Credit Cycles, Journal of Political Economy 105, 211-248.

Kung, E., 2015, Mortgage Market Institutions and Housing Market Outcomes, Working Paper.

Makarov, I., and G. Plantin, 2013, Equilibrium Subprime Lending, Journal of Finance 68, 849-879. 
Mayer, C., K. Pence, and S. Sherlund. 2009, The Rise in Mortgage Defaults. Journal of Economic Perspectives 23: 27-50.

Mayer, C., E. Morrison, T. Piskorski, and A. Gupta, 2014, Mortgage Modification and Strategic Behavior: Evidence from a Legal Settlement with Countrywide, American Economic Review $104,2830-285$.

Mian, A., and A. Sufi. 2014, House of Debt: How They (and You) Caused the Great Recession, and How We Can Prevent It from Happening Again, University of Chicago Press.

Piskorski, T., and A. Tchistyi. 2010. Optimal Mortgage Design, Review of Financial Studies 23: 3098-3140.

Piskorski, T., A. Seru, and V. Vig, 2010, Securitization and Distressed Loan Renegotiation: Evidence from the Subprime Mortgage Crisis, Journal of Financial Economics 97, 369-397.

Piskorski, T., and A. Tchistyi, 2011, Stochastic House Appreciation and Optimal Mortgage Lending, Review of Financial Studies 24, 1407-1446.

Piskorski, T., A. Seru, and J. Witkin. 2015. Asset Quality Misrepresentation by Financial Intermediaries: Evidence from RMBS Market, Journal of Finance 70, 2635-78.

Rampini, A. and S. Viswanathan, 2010, Collateral, Risk Management and the Distribution of Debt Capacity, Journal of Finance 65, 2293-2322.

Rothschild, M., and J. Stiglitz, 1976, Equilibrium in Competitive Insurance Markets: An Essay on the Economics of Imperfect Information, Quarterly Journal of Economics 90, 629-649.

Scharfstein, D., and A. Sunderam, 2016, Market Power in Mortgage Lending and the Transmission of Monetary Policy, Working Paper.

Shiller, R. J. 2008. The Subprime Solution: How Today's Global Financial Crisis Happened, and What to Do About It. Princeton, NJ: University Press.

Shiller, Robert J. and Allan Weiss, 1999, Home Equity Insurance, Journal of Real Estate Finance and Economics 19, 21-47.

Stanton, R. H., and N. Wallace, 1998, Mortgage Choice: What Is the Point?, Real Estate Economics $26,173-205$. 
Stiglitz, J. E., and A. Weiss, 1981, Credit Rationing in Markets with Imperfect Information, American Economic Review 71, 393-410.

Stroebel, J., 2016, Asymmetric Information about Collateral Values, Journal of Finance 71, 10711112. 